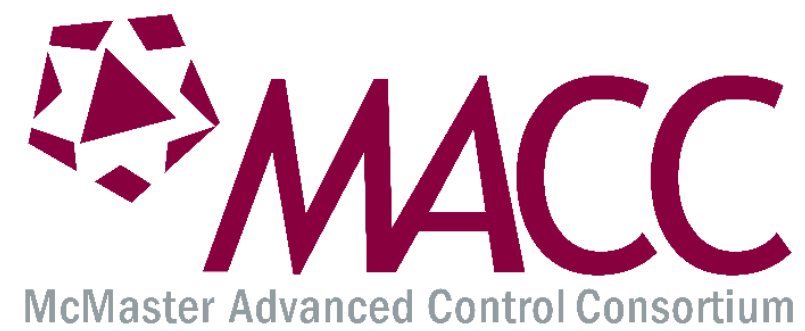

\title{
Article Pre-Print
}

The following article is a "pre-print" of an article accepted for publication in an Elsevier journal.

Lai $\mathrm{H}$, Adams TA II. A direct steam generation concentrated solar power plant with a decalin/naphthalene thermochemical storage system. Chem Eng Res Des, in press. DOI: 10.1016/j.cherd.2017.11.017 (2017).

The pre-print is not the final version of the article. It is the unformatted version which was submitted for peer review, but does not contain any changes made as the result of reviewer feedback or any editorial changes. Therefore, there may be differences in substance between this version and the final version of record.

The final, official version of the article can be downloaded from the journal's website via this DOI link when it becomes available (subscription or purchase may be required):

\section{DOI: 10.1016/j.cherd.2017.11.017}

This pre-print has been archived on the author's personal website (macc.mcmaster.ca) and/or the author's institutional repository (macsphere.mcmaster.ca) in compliance with the National Sciences and Engineering Research Council (NSERC) policy on open access and in compliance with Elsevier's academic sharing policies.

(C2017. This manuscript version is made available under the CC-BY-NC-ND 4.0 license http://creativecommons.org/licenses/by-nc-nd/4.0/

Date Archived: November 24, 2017 


\title{
A Direct Steam Generation Concentrated Solar Power Plant with a Decalin/Naphthalene Thermochemical Storage System
}

\author{
Haoxiang Lai, Thomas A. Adams II *
}

Department of Chemical Engineering, McMaster University, 1280 Main Street West, Hamilton, Ontario, Canada L8S $4 L 7$

\begin{abstract}
This study presents the design and analysis of a new integrated direct steam generation (DSG) concentrated solar power (CSP) plant with a decalin/naphthalene thermochemical storage system. Model simulations were performed in accordance to historical hourly solar radiation data over a year, using a combination of Aspen Plus v10, MATLAB 2016b, and Microsoft Excel VBA. It was found that the proposed plant feasibly stored and discharged energy, based on the solar radiation and chemical storage availability, to maintain base-load power productions (250 MW or $120 \mathrm{MW}$ ) with an overall efficiency of $14.6 \%$. The effectiveness of the designed storage system was found to be comparable to a molten salt storage system which is currently used in existing CSP plants. The proposed integrated DSG CSP plant with a decalin/naphthalene thermochemical storage system shows promise for being an alternative to existing CSP plants.
\end{abstract}

Keywords: concentrated solar power; decalin; tetralin; naphthalene; hydrogen; simulations; thermochemical storage system.

\section{Introduction}

Solar energy is an attractive source of renewable energy for electricity production as it is free and emits no direct greenhouse gas emissions. Concentrated solar power (CSP) converts solar radiation to thermal energy, which can then be used to produce power. However, just like the traditional photovoltaic solar system, CSP suffers from the intermittent nature of sunlight availability and a mismatch between peaks of available solar radiation and electricity demand. The most conventional energy storage system for CSP plants (the molten salt storage system) suffers from a small volumetric energy density ( $\sim 50 \mathrm{kWh} \mathrm{m}^{-3}$ of material), limited storage period (due to thermal losses), and high storage temperature $\left(\sim 390^{\circ} \mathrm{C}\right)$. In comparison, the thermochemical storage system studied in this work, which has not yet been commercialized, has higher volumetric energy density ( $500 \mathrm{kWh} \mathrm{m}^{-3}$ of reactant), theoretically unlimited storage period, and ambient storage temperature $[1,2]$. The challenges of this type of storage system are 
the complexity of the reactions involved and the complexity of integration with CSP plants.

With the above challenges in mind, this work investigates the feasibility and effectiveness of a direct steam generation concentrated solar power plant with an integrated decalin/naphthalene thermochemical storage system for producing base-load electricity over the course of a typical year in the southern United States. Furthermore, the designed CSP plant is also compared to an existing CSP plant with a molten salt storage system.

\subsection{Direct steam generation concentrated solar power plants}

Concentrated solar power plants are one of the key technologies for electricity generation from renewable energy. For CSP plants, parabolic trough collectors (PTC) are one of the main technologies for collecting solar energy. PTC technology uses specially curved mirrors to concentrate solar radiation collected over a wide area onto an absorbing tube where a heat transfer fluid (HTF) passes through. Compared to other collectors such as solar power tower, one advantage of PTC is the low pressure drop across the collectors [3]. The conventional HTF used in parabolic troughs is oil which is one-phase flow across the entire collectors and also easily scalable. However, steam has been shown to have higher efficiency and is non-toxic, compared to oil [4]. The drawback of steam as a heat transfer fluid for parabolic trough is the high control effort on the two-phase flow (steam/water). Direct steam generation (DSG) CSP plants have been well studied [3,5] and commercialized [4].

\subsection{Decalin/naphthalene thermochemical storage system}

Thermal energy storage (TES) systems are used in CSP plants to store excessive solar energy during the peak of solar radiation and discharge the energy when needed. They can be catalogued into sensible heat storage systems (such as molten salt), latent heat storage systems (using phase change materials), and thermochemical storage systems (applying reversible chemical reactions). As mentioned earlier, thermochemical storage systems have higher energy density than sensible heat storage system. Latent heat storage systems have volumetric density of $\sim 100 \mathrm{kWh} \mathrm{m}^{-3}$ of material, which is also lower than thermochemical storage systems. Similar to sensible heat storage systems, latent heat storage systems also typically have limited storage periods and high storage

temperatures. Therefore, thermochemical storage systems are expected to have better efficiency than the other two types of storage systems [6,7]. 
As the state-of-the-art on solar TES systems based on chemical reactions, different kinds of reversible reactions have been studied for TES systems such as metallic hydrides, carbonates system, and organic system. Pardo et al. (2014) has summarized the advantages and drawbacks of most of the thermochemical storage system in the current research filed. The drawbacks of these studied system include poor reactivity, poor reversibility, incomplete conversion of reactions, high operating pressure (up to 200 bar), and side reactions [1]. To the best of our knowledge, the decalin/naphthalene reaction pair (shown in Scheme 1) has not yet been studied as a thermochemical storage system for a CSP plant. However, the lab-scaled reaction kinetics studied by Wang et al. (2008) and Huang and Kang (1995) show that the reactions have high reactivity (under catalyst $\mathrm{Pt} / \mathrm{Y}-\mathrm{Al}_{2} \mathrm{O}_{3}$ ), high reversibility (able to achieve $\sim 100 \%$ conversion for both forward and backward reaction), relatively low operating pressure (up to 52 bar), and no side reaction (although reaction intermediates exist) $[6,8]$.

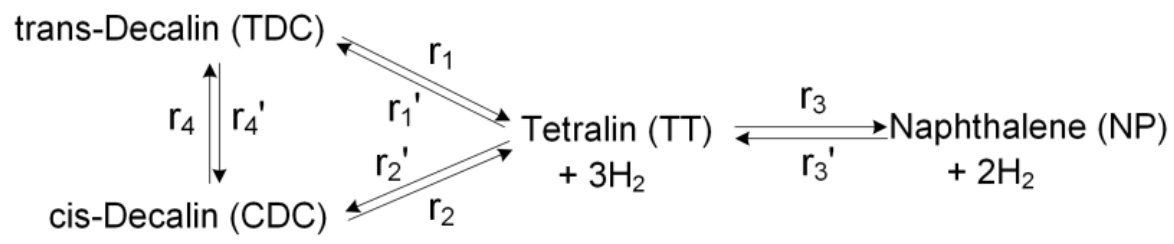

Scheme 1. Reversible reactions for the proposed thermochemical storage system. The forward reaction goes from decalin to naphthalene (from left to right), while the backward reaction is from naphthalene to decalin (from right to left).

\subsection{Concept of integrated CSP plant and decalin/naphthalene storage system}

For the purpose of storing and discharging solar energy for base-load power production through reversible chemical reactions, we propose the integration of a DSG CSP plant and a decalin/naphthalene thermochemical storage system that works as follows. When solar radiation is sufficient for base-load power production, the CSP plant stores the excessive solar energy though the decalin/naphthalene thermochemical storage system while maintaining the base-load power production. As solar radiation diminishes, the storage system discharges energy for maintaining power production on the base-load. With the advantage of high energy density and low storage temperature, the proposed integrated CSP plant and decalin/naphthalene thermochemical storage system is theoretically expected to have higher efficiency and more effective storage than CSP plants with molten salt storage system.

In this work, technical feasibility and effectiveness of the integrated DSG CSP plant and decalin/naphthalene thermochemical storage system are investigated by simulating the system in accordance to hourly solar radiation data for an entire year. Specifically, steady-state base case models are simulated using Aspen Plus v10, reactor models of 
the thermochemical storage system are developed using MATLAB 2016b, and overall simulations are performed via algorithm developed in Microsoft Excel VBA by using Excel Aspen Simulation Workbook as an interface to transfer information between models developed in Aspen Plus and MATLAB.

\section{Process Modelling}

\subsection{Process Overview}

The proposed CSP plant consists of three main components: a solar field filled with parabolic troughs, a thermochemical storage system, and a power block (Figure 1). The system was designed to be switchable between different operating modes based on the overall strategy shown in Figure 2. When solar radiation is high enough to exceed the base-load electricity production, it operates in storage mode. In this mode, water is pumped from the water tank to the solar field, gets heated through the parabolic troughs and forms superheated steam. A portion of the steam expands through the turbines and generates electricity, which completes a steam Rankine cycle. The resulting low pressure steam is then condensed and returned to the water tank. The remaining portion of steam flows through the tube side of the reactor, condensing and providing heat for the shell side where an endothermic reaction takes place. As shown in Scheme 1 , decalin reacts to form naphthalene and hydrogen gas as final products. The excessive energy that the steam carries from sunlight is then stored in the form of chemical potential. The resulting water still has relatively high temperature. Instead of returning to the water tank, it joins the inlet water to the solar field for the purpose of saving waste heat. The storage mode was designed for two different base-loads of power production (250 MW and $120 \mathrm{MW}$ ) depending on the solar radiation availability.

As the solar radiation diminishes, the discharge mode takes over. Water flows from the water tank to the tube side of the reactor, and absorbs heat from the reverse reaction. Naphthalene reacts with hydrogen reversely to form decalin, which is an exothermic reaction. Heat is released from the reaction to vaporize water and superheat the resulting steam. By feeding the steam to the power block, electricity is generated. The power block is capable of bypassing the inlet steam to reheat the steam between each turbine for higher efficiency.

The third operating mode, transient mode, is active when sunlight is present but insufficient to maintain the second base-load power production (120 MW). It is a combination of storage and discharge mode, such that the water flowing from the water tank enters both the solar field and the reactor. A portion of water gets energy from the sunlight, while the other portion is heated up by the reversed reaction. The additional 
energy discharged from the storage system compensates the insufficient solar energy to keep a base-load power production.

The objective of modelling and simulating the CSP plant is to obtain electricity production profiles according to the solar radiation profiles. To define such a system for simulation, the key design parameters and decision variables include water flow rate, operating pressure and temperature of each unit, electricity production, the amount of energy to store or discharge, the amount of reactants consumed, and sizes of major units. To reduce the degrees of freedom and to compare against a fair standard, the proposed CSP plant was designed similarly to an existing CSP plant which is the Solana Generating Station located in Arizona, US [9]. The proposed CSP plant has the same total aperture area (of parabolic troughs) as the Solana Generating Station, which is 220 hectare. The power block has a total capacity of $280 \mathrm{MW}$, also same as the existing CSP plant [10]. It consists of two sets of turbines. Each set has a total capacity of $140 \mathrm{MW}$, contributed by a high pressure turbine, an intermediate pressure turbine, and a low pressure turbine. The proposed CSP plant was designed to produce power on base-loads of either $250 \mathrm{MW}$ or $120 \mathrm{MW}$ by running either two full sets of turbines or only one set respectively, depending on the availability of solar energy.

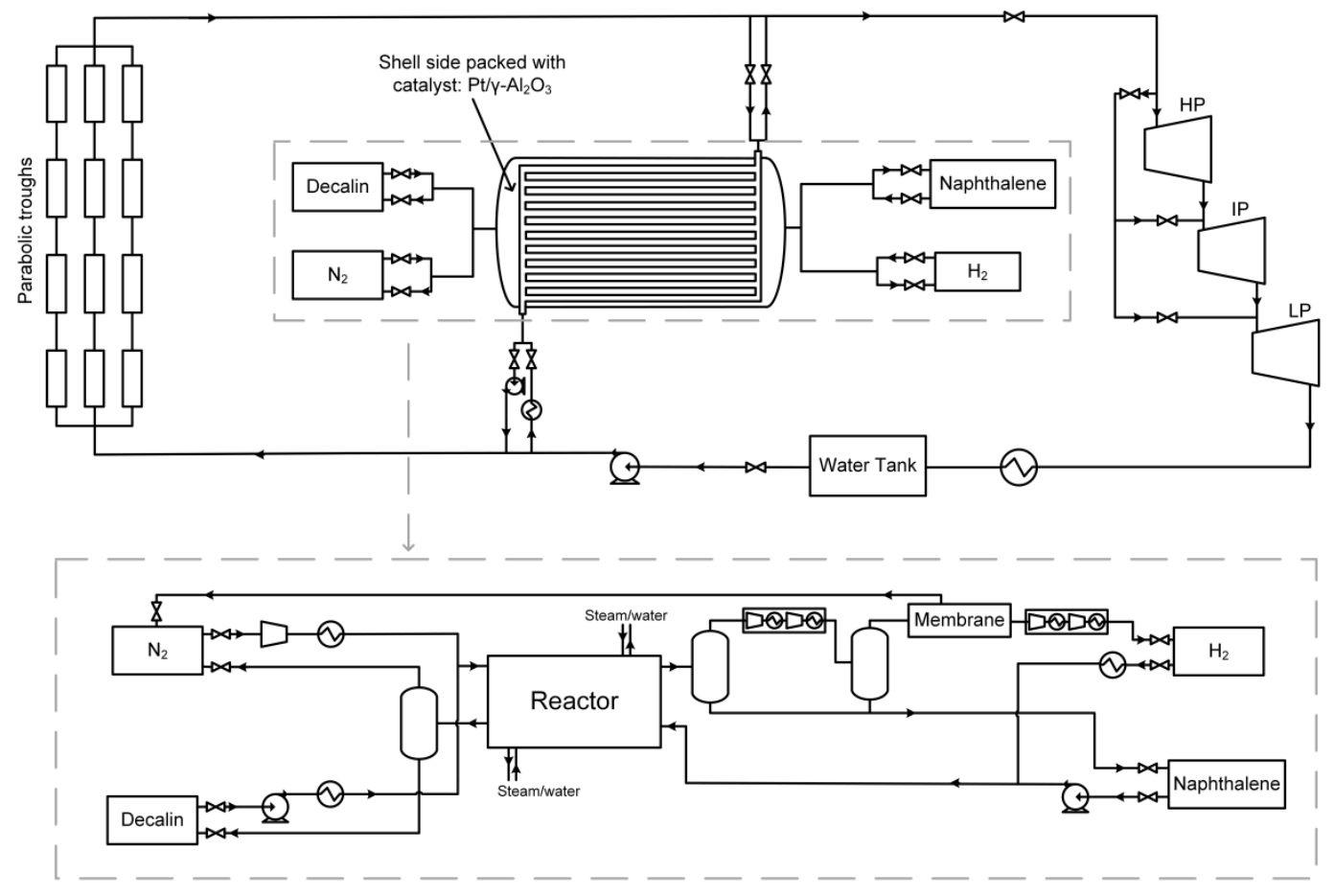

Figure 1. Scheme of the overall Concentrated Power Plant (CSP) with detailed scheme of the storage system. 


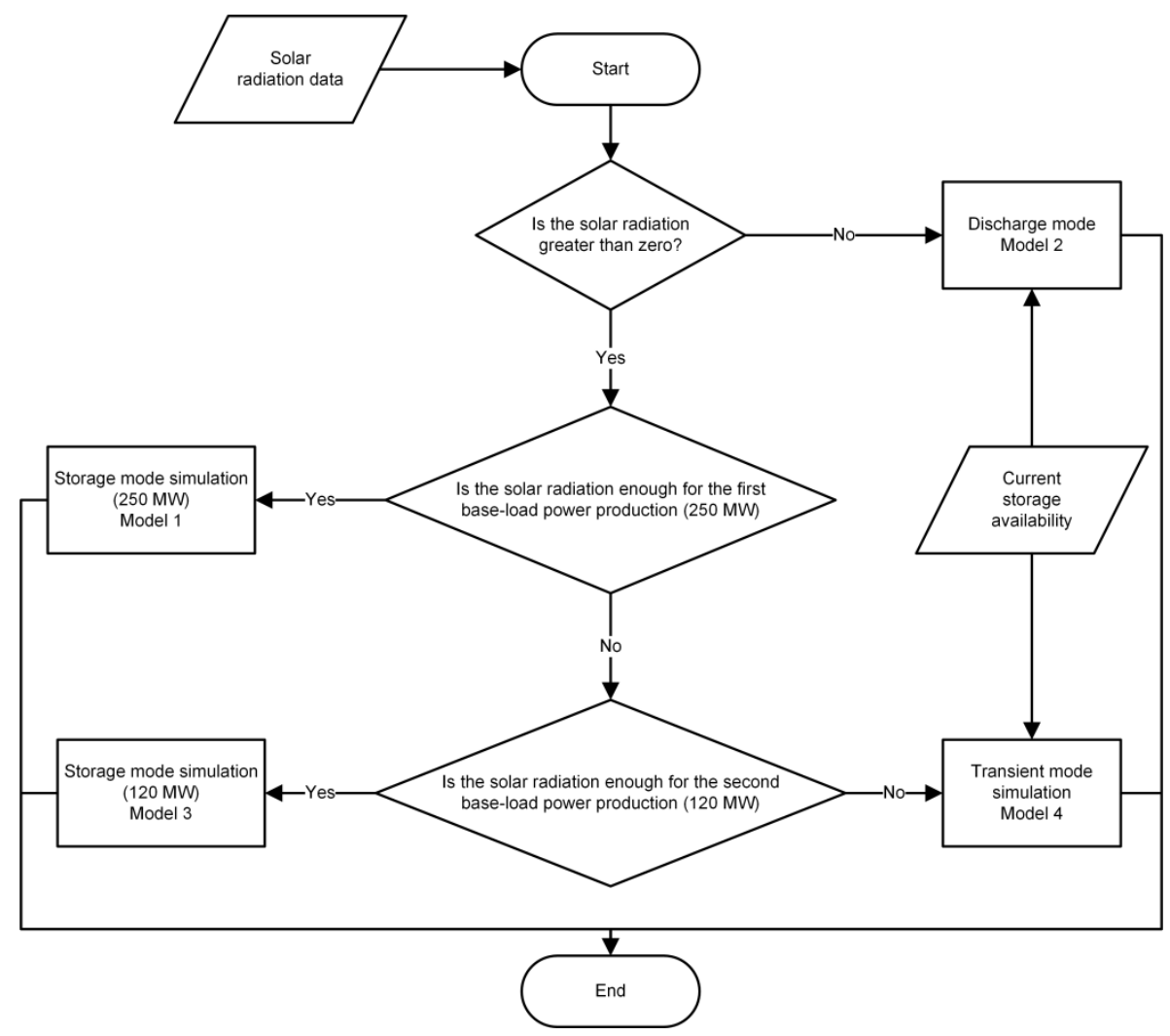

Figure 2. Overall strategy of switching the proposed CSP plant between different operating modes.

Unlike the molten salt storage system in the Solana Generating Station, the proposed thermochemical storage system consists of several shell-and-tube reactors, pre-heating steps for reactants, and separation processes for products. Steam/water is run on the tube side of the reactors, while reactions take place on the shell side which is packed with catalyst. In CSP, the steam pressure can normally get as high as 100 bar, and hence requires relatively thicker tube walls than the reaction side does [3,5]. Running the steam on the tube side requires only thick tube walls rather than thick tube and shell walls. In terms of storage, Hydrogen and nitrogen are kept in the gas phase, while decalin and naphthalene are stored as liquid. The forward reaction happens near atmospheric pressure, while the backward reaction favours high pressure up to 51.7 bar $[6,8]$. Therefore, hydrogen gas is stored at high pressure for use in the backward reaction as well as for reducing the volume of the storage tanks. Nitrogen gas is used as sweep gas for the forward reaction, but is not needed in the backward reaction. The membrane PRISM ${ }^{\circ}$ PB6050 is used to separate hydrogen from nitrogen in the forward reaction product stream [11]. The desired pressures of both the membrane feed and hydrogen storage are achieved by applying multi-stage compressors. However, 
because membrane separation is imperfect, some nitrogen is contained within the hydrogen when stored. Decalin has a normal melting point of $-30.4^{\circ} \mathrm{C}$ (trans) or $42.9^{\circ} \mathrm{C}$ (cis), so there is little risk of freezing at any point of the year in Arizona [12]. However, naphthalene is solid at room temperature since its normal melting point is $80.26^{\circ} \mathrm{C}$ [12]. In this work, naphthalene is stored above $82^{\circ} \mathrm{C}$ to avoid solids handling issues.

\subsection{Model and Simulation}

To model and simulate the proposed CSP plant, we chose historical hourly solar radiation (DNI) data for the location of Solana Generating Station in Arizona from July 2011 to July 2012 as a case study. These data were generated by the Physical Solar Model (PSM) from the National Solar Radiation Data Base (NSRDB), and is practical to use for simulation purposes since they accounted for different kinds of weather conditions such as rainy days and cloudy days [13]. Figure 3 summarizes the methodology used to develop the final design, and detailed explanations can be found in the following sections.

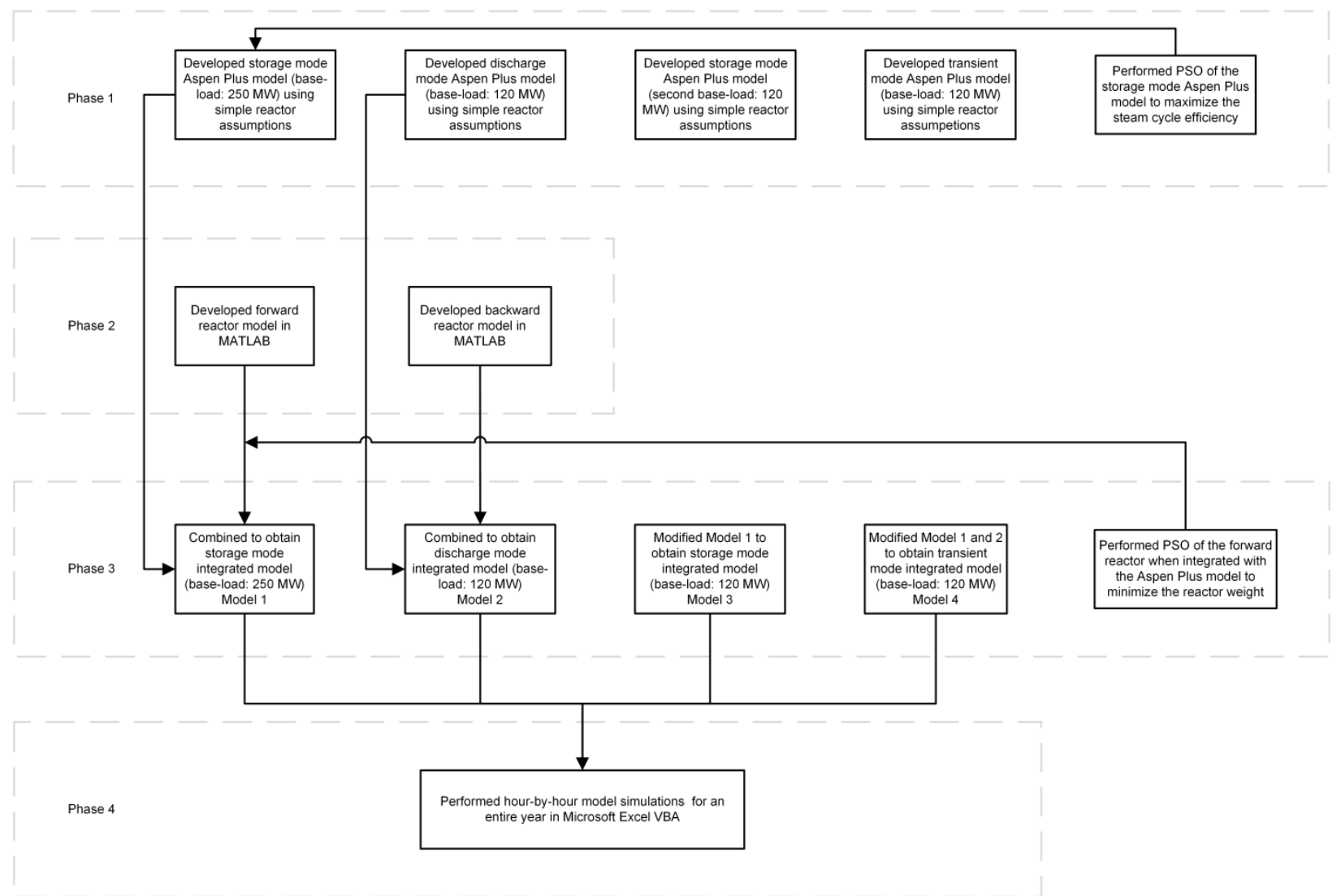

Figure 3. Summary of the methodology used to design the proposed CSP plant. 


\subsubsection{Phase 1: Steady-state Base-load Simulations}

In phase 1, by assuming $100 \%$ conversion of the reaction as well as unlimited amount of chemicals in storage, four base-case models were developed in Aspen Plus v10 with the Peng-Robinson equation of state (EOS) throughout, and STEAM-NBS for steam/water streams. The Peng-Robinson physical property package with default VLE (vapour-liquid equilibrium) parameters gave closest predictions to the experimental results when performing a model validation check on mixtures of decalin, naphthalene, tetralin, hydrogen, and nitrogen [14-17].

The decalin storage tank was assumed to hold $76 \%$ TDC and $24 \%$ CDC on a molar basis as this was the inlet concentration to the forward reaction in Wang et al. (2008) [6]. Due to incomplete membrane separation (recovering only around $78 \%$ of $\mathrm{H}_{2}$ in the feed in the permeate side), the $\mathrm{N}_{2}$ storage tank contains some $\mathrm{H}_{2}$ as a result of the recycle and storage of the retentate [11]. After solving the system mass balances, it was found that the $\mathrm{H}_{2}$ storage tank should contain $79 \% \mathrm{H}_{2}$ and $21 \% \mathrm{~N}_{2}$. Pure NP was assumed in the naphthalene tank, which was shown to be a good assumption because the forward reaction can achieve $100 \%$ conversion to NP.

The key design parameters used for Aspen Plus model simulations are summarized in Table 1. Most of the parameters were taken from references except the turbines' pressures which were determined via particle swarm optimization (PSO). PSO was run on the steam cycle part of the storage mode Aspen Plus model (base-load: $250 \mathrm{MW}$ ) to maximize the steam cycle efficiency (defined as the gross electricity production over the total energy input to the system), which is mathematically equivalent to maximizing the gross electricity production when the inlet steam conditions to the HP are fixed. The optimization problem can be formulated as below:

$$
\begin{gathered}
\max w_{H P}+w_{I P}+w_{L P}+w_{\text {pumps }}+w_{\text {compressors }} \\
\text { s.t. } v_{H P}=1, v_{I P}=1 \text {, and } v_{L P} \geq 0.95,
\end{gathered}
$$

where $w_{i}$ represents the work of each piece of equipment. Pump and compressor work is negative in the above convention. $v_{i}$ is the outlet vapour fraction (also called steam quality) of each turbine. The decision variables for this optimization were the outlet pressures of the three turbines, and the other design parameters were kept as constant.

We chose PSO for this optimization problem because it works well for black box models (the Aspen Plus model in this work) and is also parallelizable. Even though it does not guarantee the global optima, it usually gives satisfactory results [18]. The global optimum is not necessarily needed for this system, as the objective of this study is to analyze the feasibility of the concept with the requirement of finding the best possible design, and because the results of the PSO are used as initial guesses for a later optimization. The PSO code was adapted from previous work of Khojasteh Salkuyeh 
and Adams (2015) and run in MATLAB 2016b [18]. The Excel Aspen Simulation Workbook was used as an interface to connect MATLAB to Aspen Plus. The resulting turbine outlet pressures were then used in the other three base-case models, since they all had the same steam turbine design.

Table 1. Process design parameters. The asterisk $\left({ }^{*}\right)$ indicates the parameter was a decision variable determined via PSO.

\begin{tabular}{|c|c|}
\hline Unit & Key design parameters \\
\hline Solar field & $\begin{array}{l}\text { Outlet temperature: } 550^{\circ} \mathrm{C} \text {, outlet pressure: } 90 \text { bar, total } \\
\text { pressure drop: } 10 \text { bar, } \\
\text { total radiation-to-steam efficiency: } 70 \%[3,5]\end{array}$ \\
\hline High pressure turbine & $\begin{array}{l}\text { Outlet pressure: } 21.5 \text { bar *, } \\
\text { isentropic efficiency: } 87 \% \text { [19] }\end{array}$ \\
\hline Intermediate pressure turbine & $\begin{array}{l}\text { Outlet pressure: } 4.7 \text { bar *, } \\
\text { isentropic efficiency: } 88 \% \text { [19] }\end{array}$ \\
\hline Low pressure turbine & $\begin{array}{l}\text { Outlet pressure: } 1 \text { bar *, } \\
\text { isentropic efficiency: } 88 \% \text { [19] }\end{array}$ \\
\hline \multirow[t]{2}{*}{ Reactor } & $\begin{array}{l}\text { Forward reaction shell side inlet temperature and } \\
\text { pressure: } 265^{\circ} \mathrm{C}, 2.12 \text { bar; tube side inlet temperature and } \\
\text { pressure: } 550^{\circ} \mathrm{C}, 90 \text { bar }[5,6]\end{array}$ \\
\hline & $\begin{array}{l}\text { Backward reaction shell side inlet temperature and } \\
\text { pressure: } 400^{\circ} \mathrm{C}, 34.5 \text { bar; tube side inlet temperature and } \\
\text { pressure: } 285^{\circ} \mathrm{C}, 92 \text { bar }[5,8]\end{array}$ \\
\hline PRISM® PB6050 membrane & $\begin{array}{l}\text { Inlet pressure: } 8.5 \text { bar, } \\
\text { permeate pressure: } 0.2 \text { bar [11] }\end{array}$ \\
\hline Decalin storage & Temperature: $25^{\circ} \mathrm{C}$, pressure: 1 bar \\
\hline Nitrogen storage & Temperature: $25^{\circ} \mathrm{C}$, pressure: 1 bar \\
\hline Hydrogen storage & Temperature: $25^{\circ} \mathrm{C}$, pressure: 35 bar \\
\hline Naphthalene storage & Temperature: $82^{\circ} \mathrm{C}$, pressure: 1 bar \\
\hline
\end{tabular}




\subsubsection{Phase 2: Reactor Models}

The reactor was designed as a shell packed with catalyst and a number of tubes. Counter-current flows of steam/water and reactants run in the tube side and the shell side respectively.

The following assumptions were made when modeling the reactor:

- Steady-state flow

- Negligible radial variations

- Adiabatic reactor (no heat transfer to the surroundings)

- Ideal gas law for all gas-phase species

- Diffusion rates of chemicals to the catalyst surface are much faster than the reactions as assumed in kinetic study of Wang et al. (2008) and Huang and Kang (1995) $[6,8]$

- Homogeneous model for two-phase flow

A homogeneous model was assumed for two-phase flow region because the computational intensity of applying the flow pattern method for two-phase flow is too large for relatively little gain in reliability of the simulation results.

The reactor was divided into three stages for simulation purposes in both the forward and backward reaction modes since it involves a phase change region: (1) preheating/subcooling, (2) vaporizing/condensing, and (3) super-heating/cooling. The reason to divide into stages is that the equations of physical properties and energy balances for the tube side (steam/water) are different from stage to stage.

Most of the data for physical property models were retrieved from Aspen Plus V10, and are summarized in Table 2. All physical properties for water and steam were taken from NBS/NRC Steam Tables [20]. A reduced model of the default equations contained within the Peng-Robinson physical property package was used to estimate pure liquid molar heat capacity for decalin, tetralin, and naphthalene in the backward reaction. Mixture heat capacity was estimated by the average heat capacity of each component on molar basis. The estimated properties were validated with predictions from Aspen Plus using the Peng-Robinson package with less than 1\% error. By assuming a homogeneous model for two-phase flow, the mixture properties were calculated as the volume-average of properties of each component.

The reaction kinetics are based on lab-scale kinetic studies by Wang et al. (2008) and Huang and Kang (1995) for the forward reaction and backward reaction respectively. Although both the forward reaction and backward reaction use the same catalyst $\mathrm{Pt} / \mathrm{Y}$ $\mathrm{Al}_{2} \mathrm{O}_{3}$, they were studied under different conditions. Wang et al. (2008) studied the forward reaction in gas phase at atmospheric pressure for $250-350^{\circ} \mathrm{C}$, while Huang and Kang (1995) studied the liquid phase backward reaction at 17.2-86.2 bar and 200- 
$260^{\circ} \mathrm{C}[6,8]$. Therefore, reaction kinetics were written separately for the forward reaction and backward reaction.

Table 2. Method for physical property calculation.

\begin{tabular}{|c|c|}
\hline Physical property & Method \\
\hline \multicolumn{2}{|l|}{ Forward reaction } \\
\hline \multicolumn{2}{|l|}{ Pure component } \\
\hline Heat capacity & DIPPR (with parameters from Aspen Properties) [21] \\
\hline Thermal conductivity & DIPPR (with parameters from Aspen Properties) [22] \\
\hline Vapour viscosity & DIPPR (with parameters from Aspen Properties) [22] \\
\hline Enthalpy & $\begin{array}{l}\text { Integration of DIPPR with heat of formation (with } \\
\text { parameters from Aspen Properties) [21] }\end{array}$ \\
\hline \multicolumn{2}{|l|}{ Mixture } \\
\hline Thermal conductivity & Wassiljewa-Mason- Saxena equation [22] \\
\hline Vapour viscosity & Wilke \& Herning with Zipperer approximation [22] \\
\hline \multicolumn{2}{|l|}{ Backward reaction } \\
\hline \multicolumn{2}{|l|}{ Pure component } \\
\hline Heat capacity & Reduced model of Peng-Robinson equation of state \\
\hline Thermal conductivity & DIPPR (with parameters from Aspen Properties) [22] \\
\hline Liquid viscosity & DIPPR (with parameters from Aspen Properties) [22] \\
\hline Liquid phase enthalpy & Reduced model of Peng-Robinson equation of state \\
\hline Gas phase enthalpy & $\begin{array}{l}\text { Integration of DIPPR with heat of formation (with } \\
\text { parameters from Aspen Properties) [21] }\end{array}$ \\
\hline \multicolumn{2}{|l|}{ Mixture } \\
\hline Thermal conductivity & Li mixing rule with Rackett liquid volume $[22,23]$ \\
\hline Liquid viscosity & Andrade liquid mixture viscosity [22] \\
\hline
\end{tabular}

Referring to case I-2 in the work of Wang et al. (2008), the reaction rates for the forward reaction can be formulated as [6]:

$r_{1}=k_{S r 1} K_{T D C} P_{T D C} / \Delta^{7}$,

$r_{2}=k_{S r 2} K_{C D C} P_{C D C} / \Delta^{7}$, 
$r_{3}=k_{s r 3} K_{T T} P_{T T} / \Delta^{5}$,

$r_{4}=k_{S r 4} K_{C D C}^{\prime} P_{C D C} / \Omega$,

$r_{1}^{\prime}=k_{S r 1}^{\prime} K_{T T} K_{H_{2}} P_{T T} P_{H_{2}}^{3} / \Delta^{7}$,

$r_{2}^{\prime}=k_{S r 2}^{\prime} K_{T T} K_{H_{2}} P_{T T} P_{H_{2}}^{3} / \Delta^{7}$,

$r_{3}^{\prime}=k_{s r 3}^{\prime} K_{N P} K_{H_{2}} P_{N P} P_{H_{2}}^{2} / \Delta^{5}$,

$r_{4}^{\prime}=k_{S r 4}^{\prime} K_{T D C}^{\prime} P_{T D C} / \Omega$,

where $\Delta=1+K_{C D C} P_{C D C}+K_{T D C} P_{T D C}+K_{T T} P_{T T}+\left(K_{H_{2}} P_{H_{2}}\right)^{1 / 2}+K_{N P} P_{N P}$, and

$$
\Omega=1+K_{T D C}^{\prime} P_{T D C}+K_{C D C}^{\prime} P_{C D C}
$$

The rate coefficient is given by:

$k_{s i}=A_{s i} \exp \left(-E_{i} / R T\right)$,

And the adsorption constant is given by:

$K_{i}=A_{i} \exp \left(-\Delta H_{i} / R T\right)$.

For the above equations, $r_{i}$ and $r_{i}^{\prime}$ represent reaction rates as shown in Scheme 1. $P_{i}$ is the partial pressure. $A_{s i}$ and $A_{i}$ denote frequency factors. $E_{i}$ and $\Delta H_{i}$ are activation energy and heat of reaction, respectively. The above parameters were reproduced from the Arrhenius plot of rate coefficients and Van't Hoff plot of adsorption coefficients in their work [6]. Note that reversed reaction rates (represented as $r_{i}^{\prime}$ ) should also be included in the forward reaction since it is reversible.

The axial mass balances for the forward reaction are then formulated as [6]:

$\frac{d F_{T D C}}{d W}=-r_{1}+r_{1}^{\prime}+r_{4}-r_{4}^{\prime}$,

$\frac{d F_{C D C}}{d W}=-r_{2}+r_{2}^{\prime}-r_{4}+r_{4}^{\prime}$,

$\frac{d F_{T T}}{d W}=r_{1}-r_{1}^{\prime}+r_{2}-r_{2}^{\prime}-r_{3}+r_{3}^{\prime}$,

$\frac{d F_{N P}}{d W}=r_{3}-r_{3}^{\prime}$,

$\frac{d F_{H_{2}}}{d W}=3\left(r_{1}-r_{1}^{\prime}+r_{2}-r_{2}^{\prime}\right)+2\left(r_{3}-r_{3}^{\prime}\right)$,

where $F_{i}$ represents flow rate and $W$ represents the weight of catalyst which can be related to position along the axial direction of the reactor. 
Adapted from Huang and Kang (1995), the mass balances for the backward reaction are given as [8]:

$$
\begin{aligned}
& r_{1 r}^{\prime}=\frac{\eta}{\dot{V} \rho_{p}(1-\varepsilon)} k_{S r 1 r}^{\prime} F_{T T}, \\
& r_{2 r}^{\prime}=\frac{\eta}{\dot{V} \rho_{p}(1-\varepsilon)} k_{s r 2 r}^{\prime} F_{T T}, \\
& r_{3 r}^{\prime}=\frac{\eta}{\dot{V} \rho_{p}(1-\varepsilon)} k_{S r 3 r}^{\prime} F_{N P}, \\
& r_{4 r}=\frac{\eta}{\dot{V} \rho_{p}(1-\varepsilon)} k_{s r 4 r} F_{C D C}, \\
& \frac{d F_{T D C}}{d W}=r_{1 r}^{\prime}+r_{4 r}, \\
& \frac{d F_{C D C}}{d W}=r_{2 r}^{\prime}-r_{4 r}, \\
& \frac{d F_{T T}}{d W}=-r_{1 r}^{\prime}-r_{2 r}^{\prime}+r_{3 r}^{\prime}, \\
& \frac{d F_{N P}}{d W}=-r_{3 r}^{\prime}, \\
& \frac{d F_{H_{2}}}{d W}=-2 r_{3 r}^{\prime}-3 r_{1 r}^{\prime}-3 r_{2 r}^{\prime},
\end{aligned}
$$

where $r_{i r}$ and $r_{i r}^{\prime}$ are the reaction rates corresponding to Scheme 1, the "r" at the end is used to distinguish from the forward reaction. $\eta$ is a correction factor, which was assumed to be 0.8 and is explained in the next section. $\dot{V}$ is the volumetric flow rate of the mixture. $\rho_{p}$ is the density of catalyst, which was assumed to be $3.66 \mathrm{~g} / \mathrm{cm}^{3}$ as the density of $\mathrm{Y}-\mathrm{Al}_{2} \mathrm{O}_{3}$ [24]. $\varepsilon$ is the bed porosity, which is given by [25]:

$$
\varepsilon=0.38+0.073\left(1-\left(\frac{D_{\text {shell }}}{D_{p}-2}\right)^{2} /\left(\frac{D_{\text {shell }}}{D_{p}}\right)^{2}\right),
$$

where $D_{\text {shell }}$ and $D_{p}$ represent the shell diameter and catalyst particle diameter, respectively. $D_{p}$ was assumed to be $0.016 \mathrm{~m}[26]$.

Unlike the mass balances, the momentum and energy balances are the same for forward and backward reactions.

Adapted from the Ergun equation, the momentum balance is formulated as [27]:

$\frac{d P}{d W}=-\frac{v}{D_{p}} \frac{(1-\varepsilon)}{\varepsilon^{3}}\left(150(1-\varepsilon) \frac{\mu}{D_{p}}+1.75 \rho v\right)\left(\frac{1}{A_{C S}(1-\varepsilon) \rho_{p}}\right)$,

where $v, \mu$, and $\rho$ are the superficial velocity, viscosity, and density of the mixture. $A_{c s}$ is the cross-sectional area of the geometry through which the mixture flows (crosssectional area of shell subtracting cross-sectional area of tubes). 
The energy balances are formulated as Equation (27) and (28), in a form of explicit expression for the shell and tube side temperatures $[28,29]$. Although heat capacity is a function of temperature, the rate of change of heat capacities of the gases with respect to the change in catalyst weight is small. Therefore, heat capacity is assumed to be constant for a given integration step, although the value of the constant heat capacity used is recalculated every integration step using updated values of temperature.

$$
\begin{aligned}
\frac{d T_{\text {shell }}}{d W} & =\frac{1}{\sum_{i=1}^{n} F_{i} C_{p i}}\left(U \Delta T \frac{d A}{d W}-\sum_{j=1}^{m} r_{j} \sum_{i=1}^{n} \beta_{j, i} H_{i}\right) \\
\frac{d T_{\text {tube }}}{d W} & =\frac{1}{C_{\mathrm{H}_{2} \mathrm{O} \dot{M}_{\mathrm{H}_{2} \mathrm{O}}}} U \Delta T \frac{d A}{d W}
\end{aligned}
$$

Where $U \frac{d A}{d W}=1 /\left(\frac{1}{h_{f} \pi D_{\text {tube, outer }} N_{\text {tube }} \frac{d L}{d W}}+\frac{\ln \left(D_{\text {tube,outer }} / D_{\text {tube, } \text { inner }}\right)}{2 \pi k_{w} \frac{d L}{d W}}+\frac{1}{h_{H_{2}} \text { o } \pi D_{\text {tube, inner }} N_{\text {tube }} \frac{d L}{d W}}\right)$

$C_{p}$ is molar heat capacity and $C_{p \mathrm{H}_{2} \mathrm{O}}$ is the steam/water heat capacity on mass basis, at the current temperature. $H_{i}$ is the enthalpy of each component at the current temperature, which is calculated according to Table 2. They are temperature-dependent, and were estimated at the current temperature in every iteration step. $\Delta T$ is the temperature difference between the shell side and the tube side. $\beta_{j, i}$ represents the stoichiometry of species $\mathrm{i}$ in reaction $\mathrm{j} . \dot{M}_{\mathrm{H}_{2} \mathrm{O}}$ denotes the mass flow rate of steam/water, which is constant for a given hour of application. $k_{w}$ is the thermal conductivity of the tube wall, and was assumed to be $69.23 \mathrm{~W} /(\mathrm{m} \cdot \mathrm{K})$ as steel [30]. Note that equation (28) equals zero for stage 2 since the tube side temperature stays at the boiling temperature at the current pressure, by assuming that the pressure drop was small enough so that the boiling point did not change. In equation (29), the three terms in the denominator are convection through the shell side to the tubes, conduction through the tubes, and convection through the tube side to the tubes, respectively. The heat transfer coefficients are estimated as [28,31-33]:

$$
\begin{aligned}
& h_{f, \text { forward }}=\frac{k_{f}}{D_{p}}\left(0.203 \operatorname{Re}^{0.33} \operatorname{Pr}^{0.33}+0.22 \operatorname{Re}^{0.8} \operatorname{Pr}^{0.4}\right) \\
& h_{f, \text { backward }}=\alpha \frac{k_{v}}{D_{p}}\left(0.203 \operatorname{Re}_{v}^{0.33} \operatorname{Pr}_{v}^{0.33}+0.22 \operatorname{Re}_{v}^{0.8} \operatorname{Pr}_{v}^{0.4}\right)+(1-\alpha) \frac{k_{l}}{D_{p}} 0.6 \operatorname{Re}_{l}^{0.47} \operatorname{Pr}_{l}^{0.33} \\
& h_{\mathrm{H}_{2} \mathrm{O}}=\frac{k_{\mathrm{H}_{2} \mathrm{O}}}{D_{\text {tube } \text { inner }}} 0.023 \operatorname{Re}_{\mathrm{H}_{2} \mathrm{O}}^{0.8} \operatorname{Pr}_{\mathrm{H}_{2} \mathrm{O}}^{0.3}
\end{aligned}
$$


Where the Reynolds number $\operatorname{Re}=\rho v D / \mu$ and the Prandtl number $\operatorname{Pr}=\mu C_{p} / k$. The physical properties equations in Table 2 were used in the computation of $\operatorname{Re}$ and $\operatorname{Pr}$ such that they account for the flow mixture and change across the axial position of the reactor. The diameter in the expression of Reynolds number should be the catalyst particle diameter for the shell side, and the tube inner diameter for the tube side. In equation (31), $\alpha$ is the volume averaged void fraction or called gas hold up. It is defined as the volumetric flow rate of gas divided by the sum of volumetric flow rate of both gas and liquid. It was also used to estimate physical properties of the two-phase mixture. In equation (31), $\alpha$ was used to joint correlations for gas phase and liquid phase [34]. A single heat transfer correlation for two-phase flow in such geometry has not yet been studied to our knowledge.

The forward and backward reaction models were developed in MATLAB 2016b, and ode23s functions were used for the ODEs in the models. The known boundary conditions of the ODEs are the known conditions (flow rates, temperatures, pressures, compositions) of the tube and shell inlet streams (as resulting from Aspen Plus simulations). However, because the reactor uses counter-current flow, this does not result in an initial value problem that can be integrated directly with an ODE solver in MATLAB. Moreover, the total reactor weight $\mathrm{W}$ is not known a priori. Instead, an initial value problem was formulated by defining $W=0$ to be the shell inlet, with known boundary conditions on the shell side defined at $\mathrm{W}=0$, such as $\left.T_{\text {shell }}\right|_{W=0}$, and $\left.P_{\text {shell }}\right|_{W=0}$. The tube side boundary conditions at $\mathrm{W}=0$ (the tube outlet), such as $\left.T_{\text {tube }}\right|_{W=0}$, and $\left.P_{\text {tube }}\right|_{W=0}$, which are unknown, were guessed, resulting in a solvable initial value problem. The simulation was then integrated from $\mathrm{W}=0$ to $\mathrm{W}=\mathrm{W}$ max (where the reaction achieved $95 \%$ conversion), and the resulting computed tube side variables at $\mathrm{W}=\mathrm{W}_{\max }$ were compared against the known values (the tube inlet conditions). If the difference was greater than some small tolerance, new guesses were generated for the tube side variables at $\mathrm{W}=0$ and the procedure was repeated iteratively until convergence was achieved. Note that with this approach, the forward reaction starts from stage 1 to 3 with $\mathrm{W}=0$ at the start of stage 1 , but the backward reaction starts from stage 3 to 1 with $W=0$ at the start of stage 3 .

Because the model equations are different in each stage, and the length of each stage (in terms of $\mathrm{W}$ ) is not known a priori, the integration algorithm included checks to detect a stage change (for example, when the tube temperature drops below the boiling point). The step occurring after the detected event was rejected and the previous time-step results were used to re-initialize the problem starting at the beginning of the new stage. Because the integration step sizes were small, advanced techniques to adjust integration step-sizes to find the event location with high precision were not used.

For the backward reaction, the rate of heat release from the exothermic reaction is far faster than the rate of heat transfer to the tube side. This makes heat management an 
important consideration in the design of the reactor. For example, feeding all of the reactants (mainly NP and $\mathrm{H}_{2}$ ) together at the shell inlet results in unreasonably large temperatures in the shell side near the entrance. To solve this problem, the proposed design feeds all of the $\mathrm{H}_{2}$ without NP at the shell inlet. There are many NP injection points into the shell down the length of the reactor in which a small amount of NP at its storage temperature $\left(82^{\circ} \mathrm{C}\right)$ and pressure of the reaction are injected. The injection locations were determined during ODE integration by event detection in a similar manner to detecting the onset of a new stage: whenever the shell temperature dropped below $400^{\circ} \mathrm{C}$, between 0.5 and $2 \mathrm{kmol} / \mathrm{hr}$ (which varied along the length of the reactor) of NP was injected at the current $\mathrm{W}$, which typically resulted in a local temperature increase to approximately $1-5^{\circ} \mathrm{C}$ (also varied along the length of the reactor). The NP injections were treated as inlet to the next ODE integration, therefore no change was made to the mass balances while the enthalpy term of the injection was added to the energy balances. The actual amount to inject at each point was determined manually through a trial-and-error process. The correction factor $\eta$ is used to account for this change as the reaction might be slower due to additional mixing when NP is injected.

\subsubsection{Phase 3: Integration of base-case models}

To integrate the base-case Aspen Plus models with the reactor models, the sequence steps shown in Figure 4 were followed (the upper part). PSO was implemented on the forward reaction mode to minimize the reactor weight with a constraint that the reaction conversion achieved $95 \%$. The optimization problem was formulated as follows:

$$
\begin{gathered}
\min \rho_{\text {steel }} \pi L\left(\left(D_{\text {shell,outer }} / 2\right)^{2}-\left(D_{\text {shell,inner }} / 2\right)^{2}+N_{\text {tube }}\left(\left(D_{\text {tube, outer }} / 2\right)^{2}\right)-\left(D_{\text {tube, inner }} / 2\right)^{2}\right) \\
\text { s.t. }\left(\left.F_{T D C}\right|_{W=0}-\left.F_{T D C}\right|_{W=W_{\text {max }}}\right) /\left.F_{T D C}\right|_{W=0} \geq 0.95,
\end{gathered}
$$

where the density of the steel $\rho_{\text {steel }}$ was assumed to be $7.8 \mathrm{~g} / \mathrm{cm}^{3}[35] . L$ is the reactor length. The decision variables included shell inner diameter, tube outer diameter, the tube-sheet layouts (square pitch or triangular pitch), and the reactor length. The reactor length (or equivalently, the catalyst weight) was allowed to be as long as necessary for the reaction to achieve 95\% conversion. Peters and Timmerhaus (1991) summarize different conventional combinations of shell inner diameters, tube outer diameters, and tube-sheet layouts; and the maximum number of tubes for each combination [36]. The shell outer diameter and tube inner diameter were calculated by assuming that the wall thickness was $1 / 20$ of the inner diameter [37].

Since the optimization problem was formulated to include various shell-and-tube configurations, a number of infeasible points were expected such as too large pressure drop that caused the reaction to terminate. Hence, PSO was a suitable optimization tool 
for this problem as it could identify feasible points when it searched the whole space and found very good options among the feasible points. Again, it did not guarantee a global optimum, but only good feasible results were needed.

By following the sequence in the upper part of Figure 4, the models converged when the shell inlet was 1.17 bar and $265^{\circ} \mathrm{C}$ for the forward reaction mode and 51.7 bar and $400^{\circ} \mathrm{C}$ for the backward reaction mode. However, the compressor power consumption predicted by the integrated model was very high (37\% of the net power production) due to the pressure increase from 1 to 8.5 bar (for the membrane operation) and from 0.2 to 52 bar (for $\mathrm{H}_{2}$ storage). To reduce the power usage for this part, the shell inlet pressure for the forward and backward reaction modes were changed to 2.12 bar and 34.5 bar respectively, while keeping the temperature settings unchanged. By reducing this pressure difference, the power consumption of the compressors was reduced to $30 \%$ of the net power production. However, a longer reactor is required to achieve the target reaction conversions. Hence, the maximum reactor length constraint on Figure 4 was changed to $20 \mathrm{~m}$ for model convergence. In addition, it was assumed that the forward reaction kinetics are still applicable at 2 bar, even though they were only developed at about 1 bar [6]. Similarly, the relationship between rate constants and temperature of the backward reaction for 34.5 bar were assumed to be the same as that for 51.7 bar, based on the linearity of the Arrhenius plot in Huang and Kang (1995). Also, linear extrapolation of rate constants was assumed for temperatures out of the range of the study [8].

By integrating the storage mode Aspen Plus model with the MATLAB forward reaction model, and the discharge mode model with the backward reaction model; two integrated models were obtained: Model 1 and Model 2. However, in order to converge the model equations which relate to chemical compositions of the storage tanks, the Aspen Plus and MATLAB portions of the models had to be solved iteratively. The sequence shown in the bottom of Figure 4 was followed to integrate the storage and discharge mode models (Model 1 and Model 2) to ensure the chemical compositions in each tank in the two models converged. Model 3 (storage mode with second base-load: $120 \mathrm{MW}$ ) was then obtained by changing the gross power production setting of Model 1 from $250 \mathrm{MW}$ to $120 \mathrm{MW}$. Model 4 (transient mode with base-load: $120 \mathrm{MW}$ ) was the combination of Model 2 and the solar-steam cycle part of Model 1. Note that these models are representative of only one reactor, although the actual design uses many identical reactors. For example, Model 3 requires around 49 reactors (treated as continuous variables in Phase 3 and corrected in Phase 4) in parallel operating in backward reaction mode to achieve the base-load power production. 

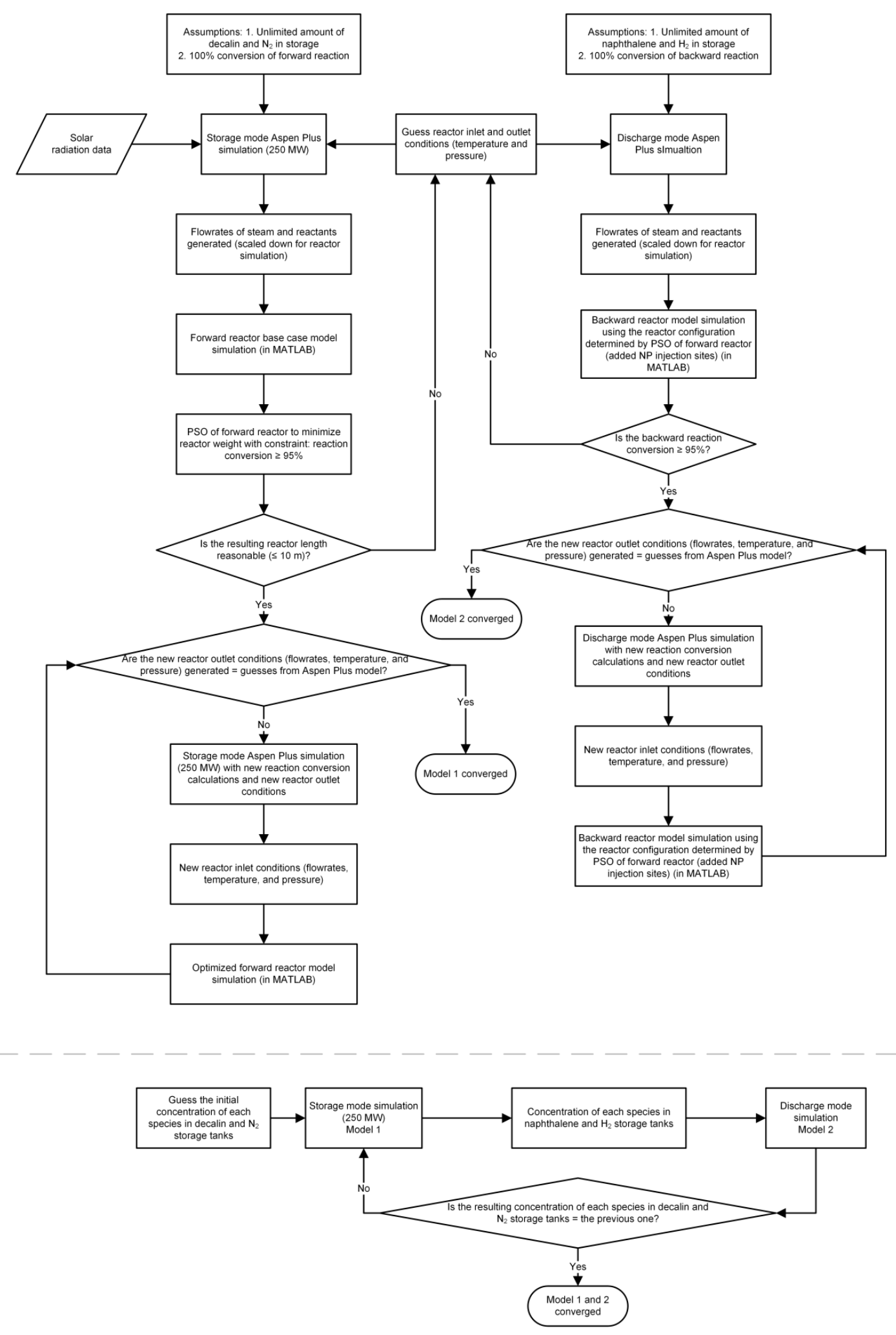

Figure 4. The simulation sequence for integrating the base-case models. The upper part is the sequence for integrating base-case Aspen Plus models with the reactor models. The lower part is the sequence for integrating the storage and discharge mode models. 


\subsubsection{Phase 4: Overall System Simulations}

A simulation strategy algorithm was developed in Microsoft Excel VBA (Visual Basic for Applications) by following the sequence shown in Figure 5. The Excel Aspen Simulation Workbook was used as an interface to connect the VBA algorithm with the base case models (Model 1 to 4). As shown in Figure 5, the hourly solar radiation data (from July $1^{\text {st }}$ 8:00 am, 2011 to July $1^{\text {st }}$ 7:00 am, 2012) were taken as inputs to the VBA algorithm for Round 1 simulations. For each solar radiation data point, the algorithm chose an appropriate model among Model 1 to 4 , based on the current solar radiation and chemical storage. These steady-state base case models were set to produce power on base-loads of either $250 \mathrm{MW}$ or $120 \mathrm{MW}$ if possible, and they could also produce power below the base-loads depending on the current available solar radiation and chemical storage. As outputs to the VBA, each case model returned the number of reactors used (as continuous variable) and the key parameters such as steam flowrate in the solarsteam cycle, steam flowrate and reactant flowrates to the reactor. By following the algorithm, 8784 steady-state simulations were run case-by-case according to the hourly solar radiation data in Round 1. However, it was not practical to have non-integer number of reactors. Hence, Round 2 simulations were run by taking the rounded numbers of reactors and the key parameters from Round 1 as input data. In Round 2, each case from Round 1 was re-run with the new input data. The chemicals storage availability was also updated between each case simulation since the simulation results were different than those in Round 1 . The resulting electricity production of each case was also different than that in Round 1. For example, a case that produced base-load of $250 \mathrm{MW}$ in Round 1 would result in producing slightly more or less than the base-load in Round 2. 

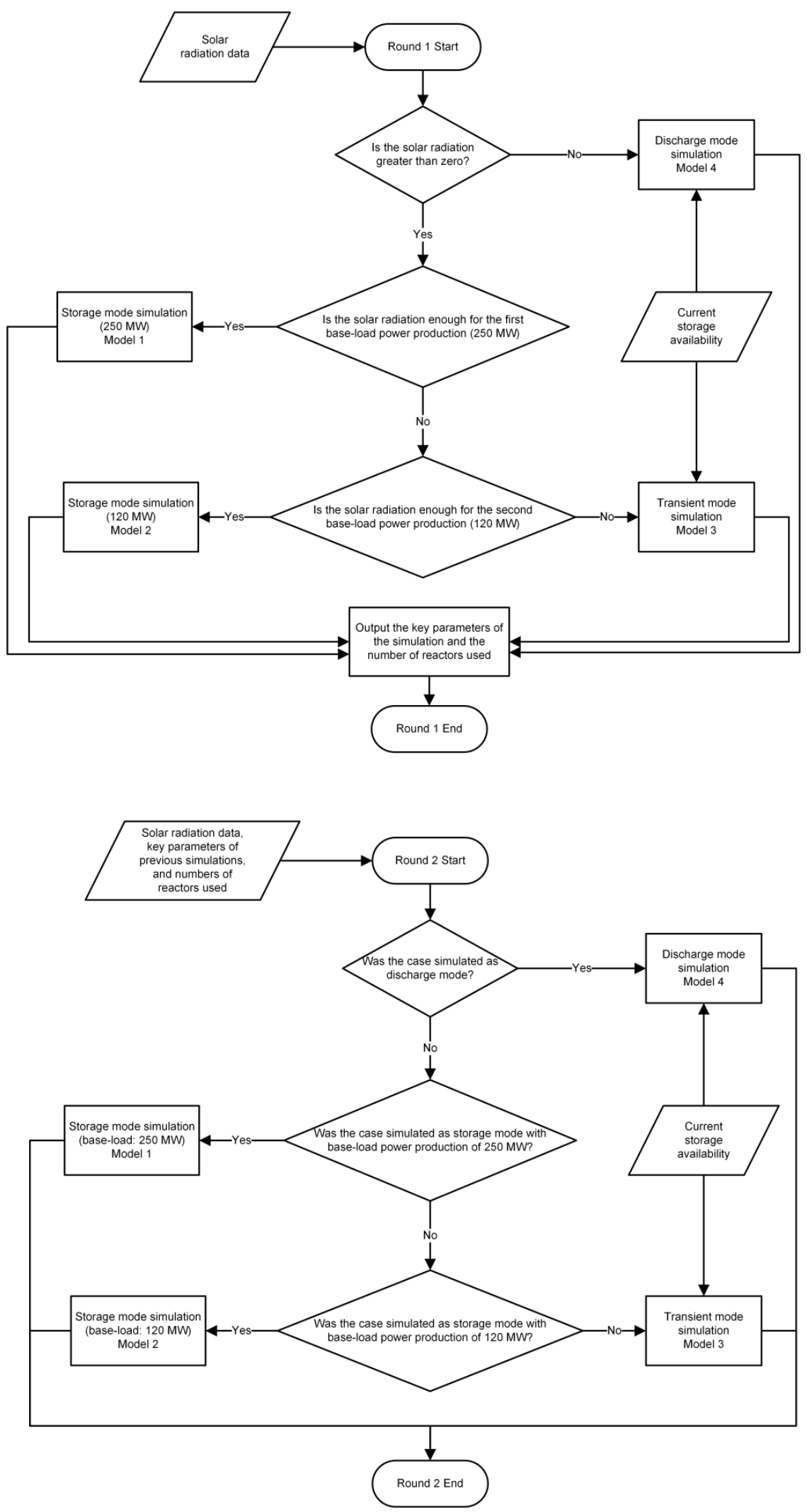

Figure 5. The VBA sequence for the overall system simulations. 


\section{Results and Discussion}

\subsection{Reactor Results}

The final reactor configuration chosen is shown in Figure 6 . The shell was designed to be packed with catalyst particles and 137 tubes arranged in a square pitch. It was determined that 67 injection sites located along the reactor length $(9.37 \mathrm{~m}$ long) on the shell wall with an average distance of $0.14 \mathrm{~m}$ in between each site. These injection sites were used only for the backward reaction. The forward reaction needed a longer reactor to complete the reaction with satisfied conversion, which was determined to be $18.74 \mathrm{~m}$ in length (double the length of the designed reactor). In practice, the forward reaction would require two reactors in series (connecting two designed reactors head-to-tail) in operation as shown in Figure 6.

The simulation results showed that the worst-case number of $9.37 \mathrm{~m}$ reactors was 282 (during storage mode from $1 \mathrm{pm}$ to $2 \mathrm{pm}$ on March 2, 2012) if the system were designed to capture all available excessive solar energy while providing base-load power production within that hour. The total footprint of 282 reactors is around 0.1 hectare, which is $1 / 20$ of the footprint of the solar field. In practice, one would likely construct the system with much fewer reactors and simply not recover all available solar energy during the most intense times of the year. For example, by constructing only 180 reactors, one could still recover $92 \%$ of all available excessive solar energy in the year. Determining the optimal number of reactors with this trade-off in mind is not trivial and out of scope of this work, which would require a complete economic analysis under the uncertainty of solar intensity variations, market prices, electricity demand, and other factors.

The discharge mode and transient mode required less than 50 of the $9.37 \mathrm{~m}$ reactors in the worst case. The forward reaction (storage mode) requires much more reactors than the backward reaction (discharge or transient mode) because the forward reaction needs a large amount of $\mathrm{N}_{2}$ as sweep gas to maintain the desired conversion. As future work, further kinetic studies on the reaction at different pressures, temperatures, and sweep gases might help to identify better reaction conditions to use based on the system as a whole.

Figure 7 shows the temperature profiles and the flowrate profiles of both the forward reaction and backward reaction in a single reactor (or two-reactor-in-series for the forward reaction). The arrows on the temperature profiles represent the direction of the flows. For the forward reaction, reactants (mostly TDC as the major product of the backward reaction, $\mathrm{N}_{2}$ as sweep gas which is not shown on the figure, and trace other species) enter through shell side at $265^{\circ} \mathrm{C}$ and pass through stage 1 to 3 , absorbing heat from the tube side and forming NP and $\mathrm{H}_{2}$. The products leave the reactor at $361.5^{\circ} \mathrm{C}$ with $100 \%$ conversion of both TDC and CDC. The selectivity to NP and TT 
were found to be $99.88 \%$ and $0.12 \%$, respectively. In the counter-current direction, steam at $550^{\circ} \mathrm{C}$ enters stage 3 of the reactor on the tube side; and releases heat until its dew point $\left(303.38^{\circ} \mathrm{C}\right.$ at $\left.90 \mathrm{bar}\right)$ is reached, where stage 2 begins [20]. The temperature stays constant for the phase-change stage and drops to $301^{\circ} \mathrm{C}$ at the other end of the reactor.

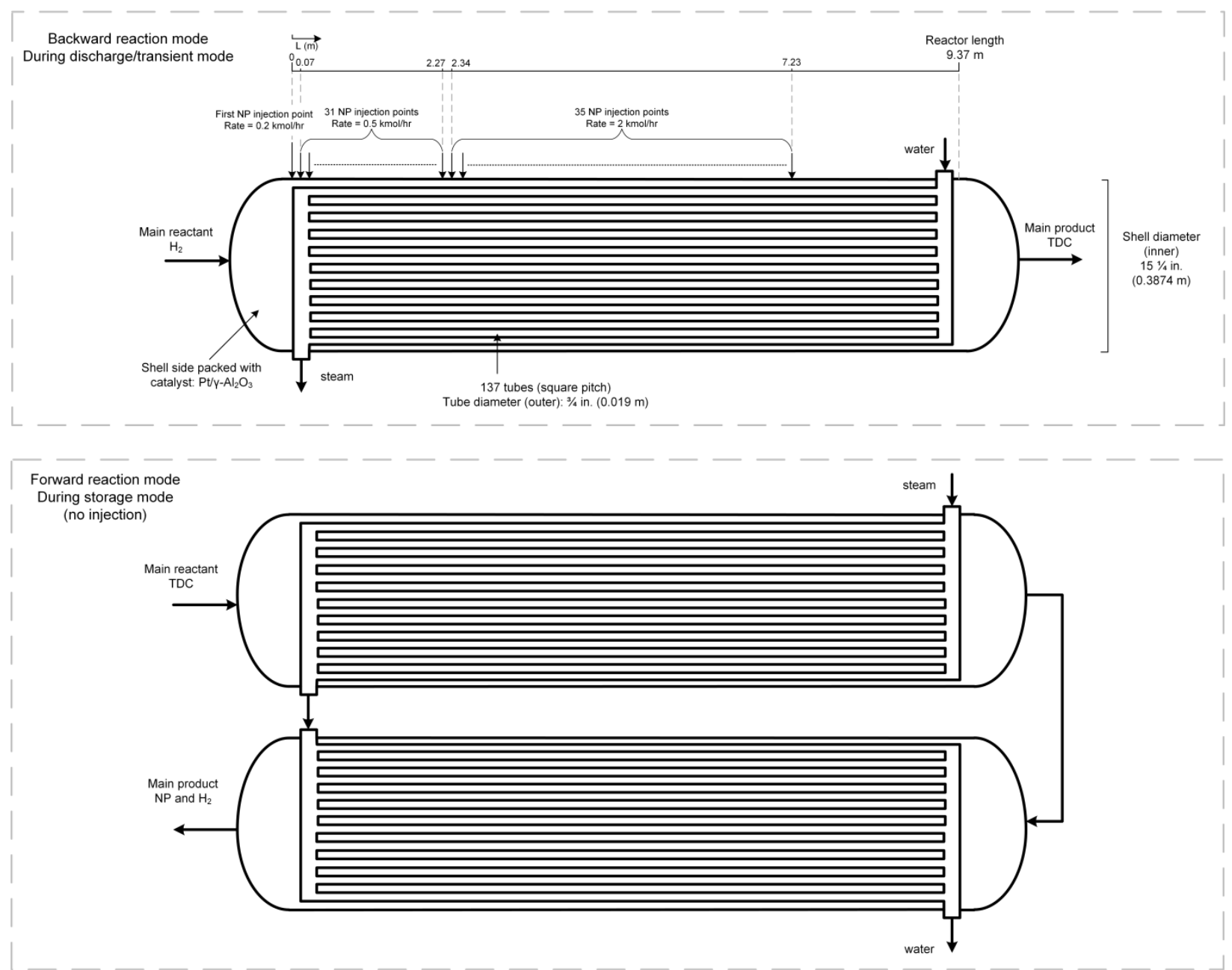

Figure 6. Reactor configuration specifications.

While running the backward reaction, $\mathrm{H}_{2}$ with a small amount of $\mathrm{N}_{2}$ (left from the membrane separation) enters stage 3 on the shell side at $400^{\circ} \mathrm{C}$, which is the opposite direction of the forward reaction (still shown from left to right on the figure). NP with trance TT are then injected through the injection sites. As can be seen on the figure, each step change on the NP flowrate profile represents an injection. For better illustration of the flowrate profiles of NP, CDC, and TT, Figure 8 shows flowrate profiles without $\mathrm{H}_{2}$ and TDC as well as a magnified window of stage 3. The specifications of 
injection can be seen in Figure 6 . The injections successfully keep the reaction temperature around $400^{\circ} \mathrm{C}$ for most of the time, so that the backward reaction completed with $100 \%$ conversion of NP. The selectivity to TDC, CDC, and TT were computed to be $97 \%, 2 \%$, and $1 \%$, respectively.
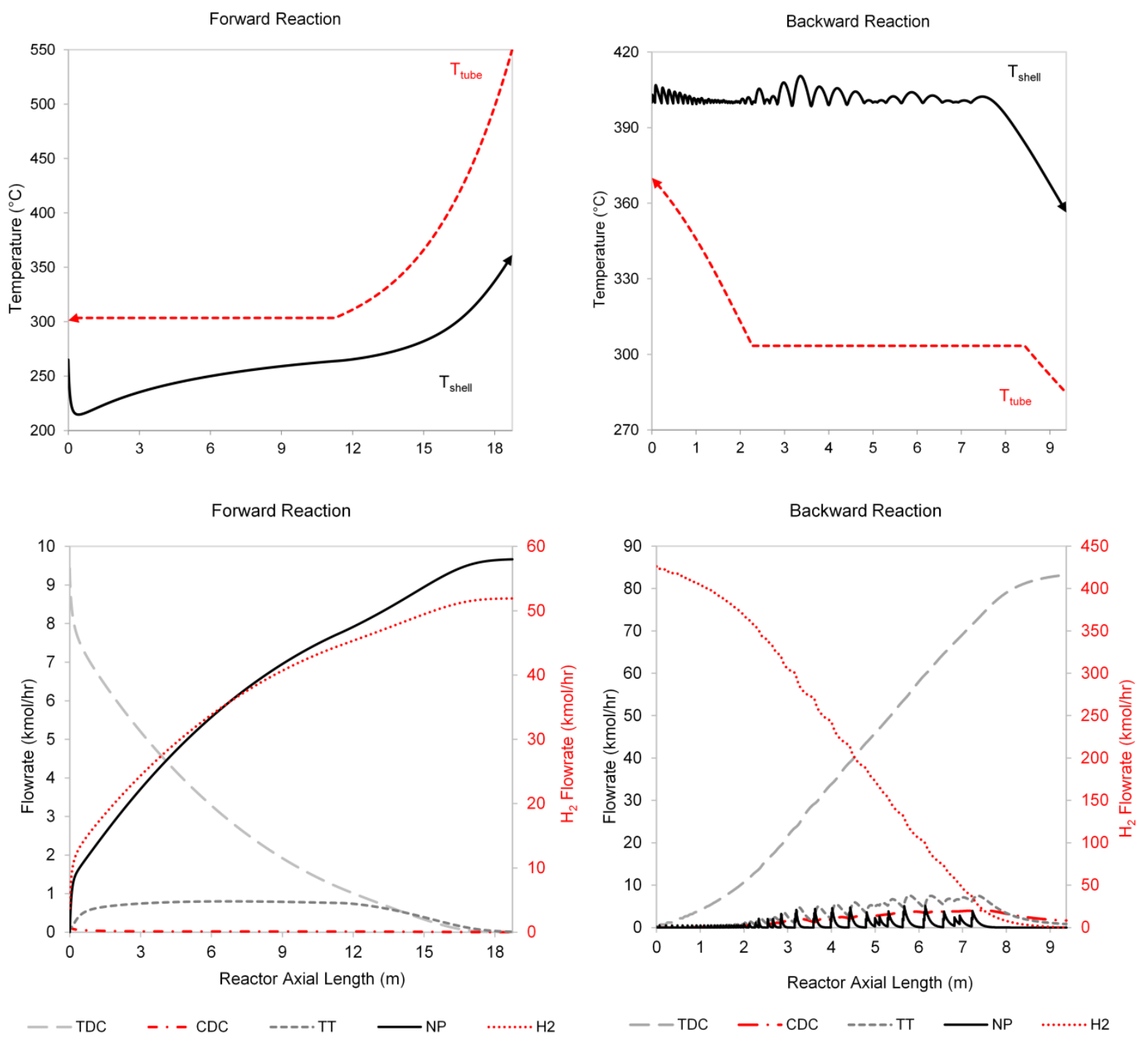

Figure 7. Axial profiles of temeperature and reactant flowrates during forward reaction and backward reaction. 

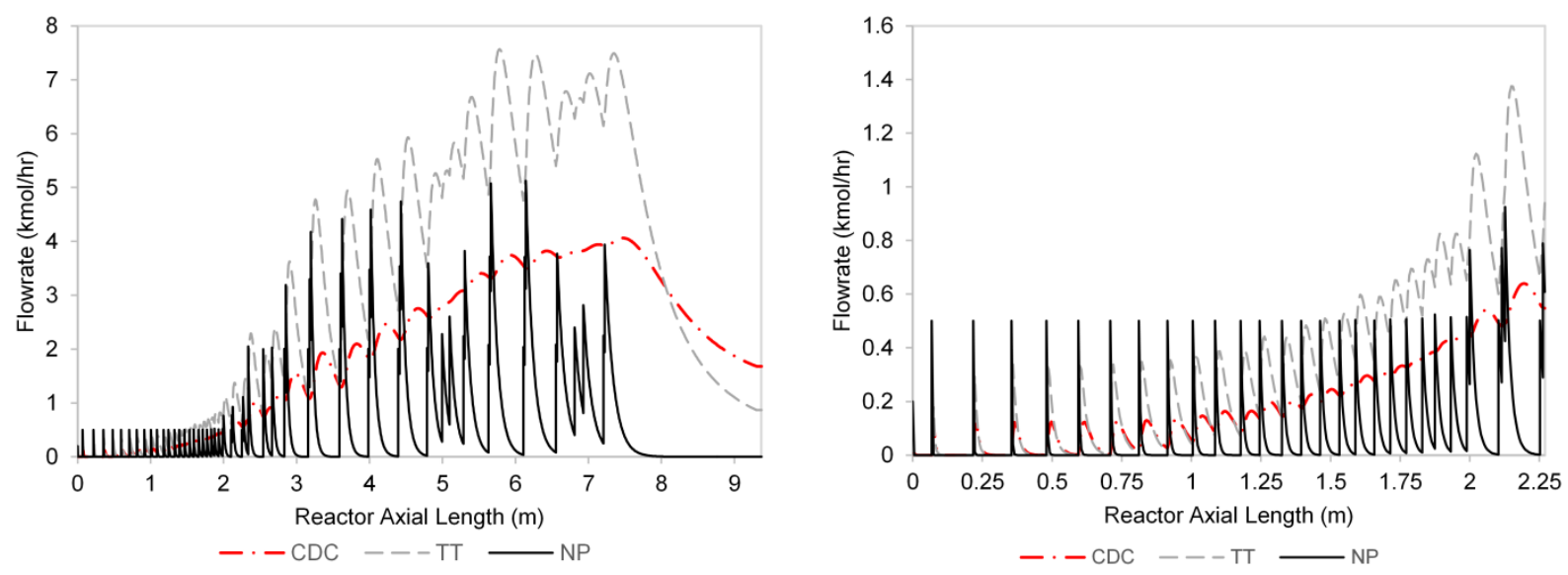

Figure 8. Axial profiles of reactant flowrates during the backward reaction (only showing cisdecalin, tetralin and naphthalene) and a magnified window of stage 3 .

\subsection{Overall System Results}

The results of the overall system simulations showed that the predicted total annual production from July $1^{\text {st }}, 2011$ to July $1^{\text {st }}, 2012$ was 861 GWh. The overall plant efficiency was found to be $14.6 \%$, which is defined as the total gross power production over the total available solar energy in the year. Comparable to the existing CSP plant, Solana Generating Station, the projected production of the Solana plant was $944 \mathrm{GWh}$ and the actual production from 2014, 2015, and 2016 was $604 \mathrm{GWh}, 719 \mathrm{GWh}$, and $644 \mathrm{GWh}$, respectively $[38,39]$. The monthly production profile predicted by the model is shown in Figure 9. The system produced much more power in summer than winter as expected. To illustrate the electricity production on daily basis, Figure 10 shows the daily model predicted production for the month of March, 2012. It can be seen that the power production varied according to the weather conditions.

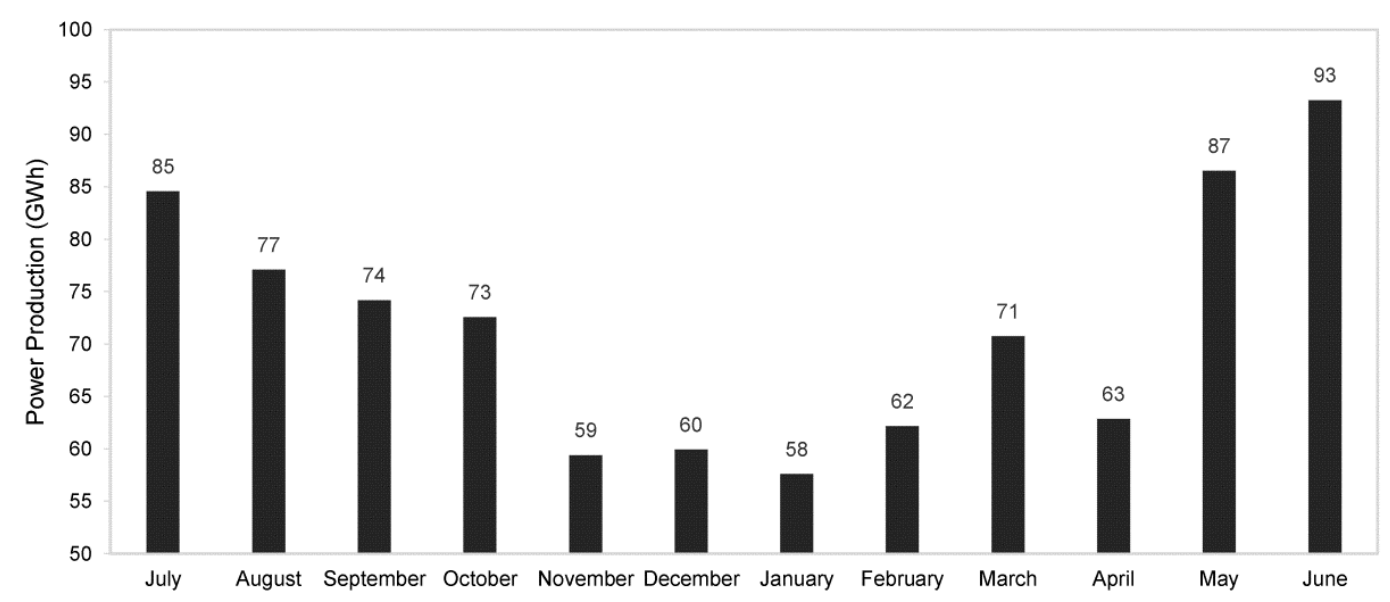

Figure 9. Model predicted monthly electricity production. 


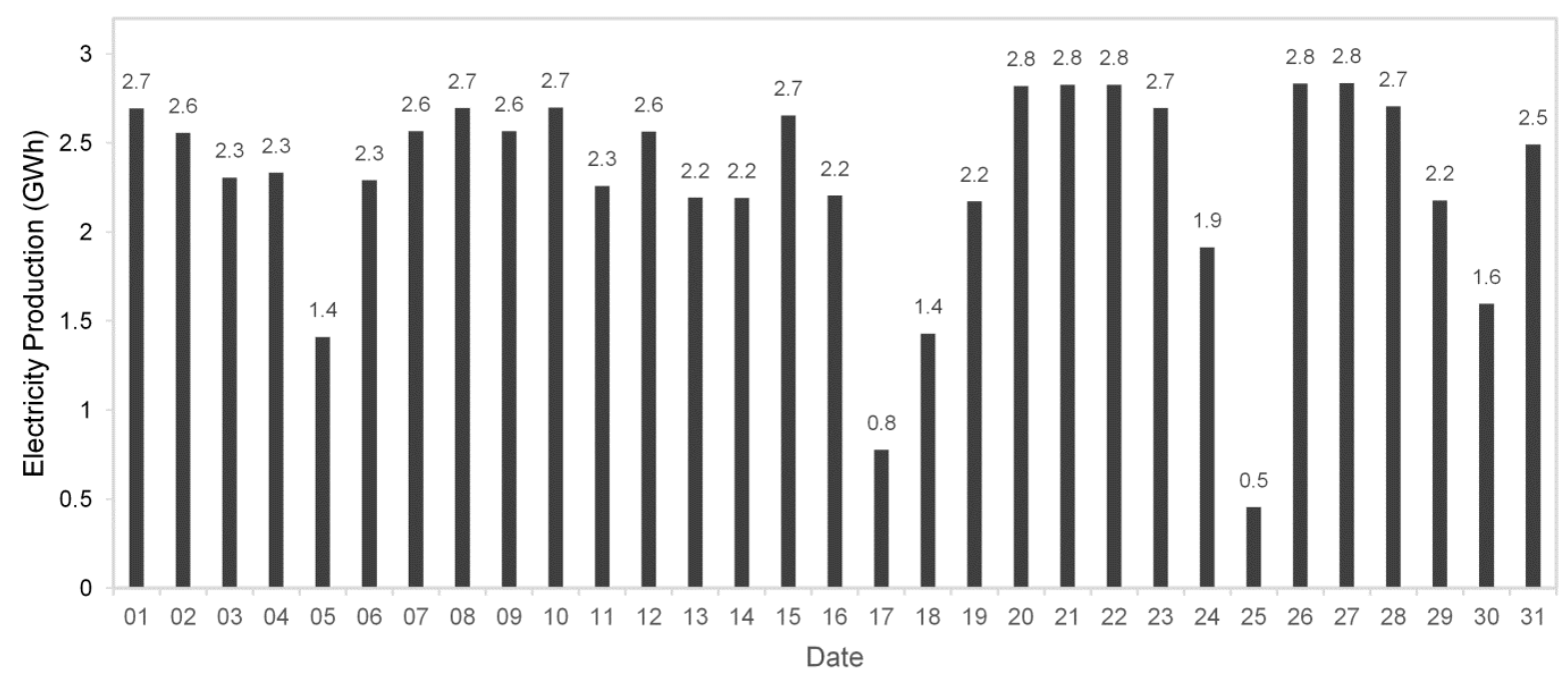

Figure 10. Model predicted daily electricity production in March, 2012.

Figure 11 shows the model predicted hourly electricity production profile (the bottom figure) on a typical summer day, July $8^{\text {th }}, 2011$. At $6 \mathrm{am}$, the plant produced as much power as the sunlight could supply (below $120 \mathrm{MW}$ ). In the next hour, the available solar energy was enough for the second base-load production (120 MW) and the excessive solar energy was stored through the thermochemical storage system. From 8 am, the system produced power at $250 \mathrm{MW}$ and stored the extra solar energy until $6 \mathrm{pm}$. The transient mode was switched on at $7 \mathrm{pm}$. Energy was discharged from the storage system to compensate the insufficient sunlight during this hour, to produce power at 120 MW. The discharge mode took over at $8 \mathrm{pm}$ as the sunlight diminished, lasting for two hours until the stored energy was depleted.

For illustrative purposes, Figure 11 includes an example power demand curve that was taken and scaled from historical grid data for Ontario, Canada [40] (since power demand curves for the area served by the Solana station were unavailable to our knowledge). This figure highlights the mismatch between the peaks of sunlight and power demand, showing that the proposed CSP plant could still produce power in the evening (without adequate sunlight) while the power demand is still high. Although power demand curves were not considered in this work, designing and simulating the CSP plant for peaking power demand might be considered in future work.

Accordingly, the volume profiles of the main species TDC and $\mathrm{H}_{2}$ in the storage tanks on July $8^{\text {th }}, 2017$ can be seen as the upper part of Figure 11. The TDC volume continuously decreased as the energy was being stored through the forward reaction until $6 \mathrm{pm}$. It started to fill up at $6 \mathrm{pm}$ since TDC was produced by the backward reaction during the transient or discharge mode. The $\mathrm{H}_{2}$ volume, on the contrary, increased and then decreased in accordance with the energy storing and discharging in the storage 
system. Note that the TDC volume did not recover to its original level in a daily cycle. The root cause was the incomplete membrane separation when separating $\mathrm{H}_{2}$ from $\mathrm{N}_{2}$ (separating around $78 \%$ of $\mathrm{H}_{2}$ ). $\mathrm{H}_{2}$ became the limiting reactant for the backward reaction. NP was left over from the reaction since it was in excess, which caused the incomplete recovery of TDC. In a result, the system kept consuming TDC and building up NP.
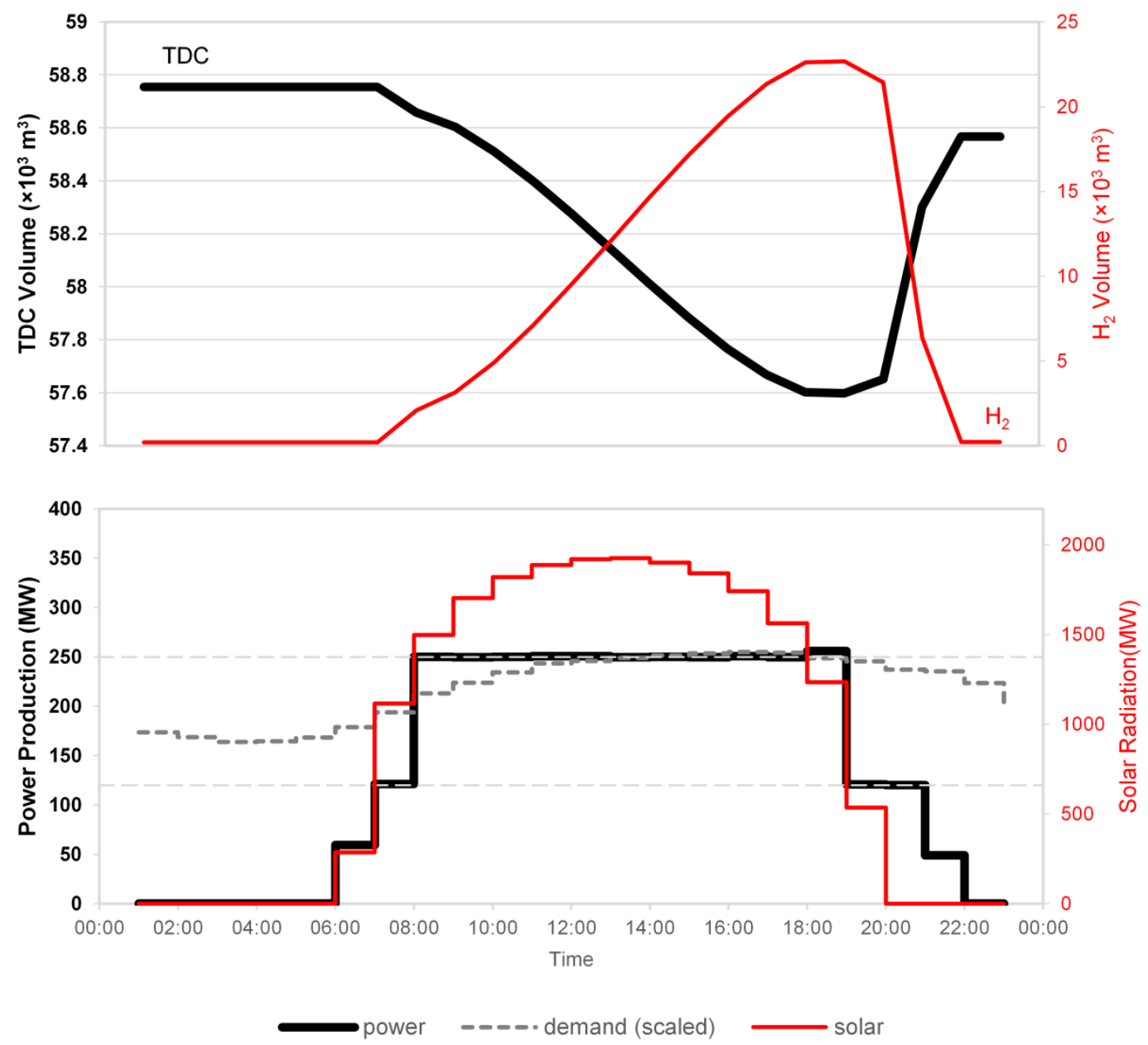

Figure 11. Model predicted electricity production profile and storage volume profiles of chemicals on July $8^{\text {th }}, 2011$. On the bottom figure, power production and demand curves are read from the primary axis on the left, and solar radiation is read from the secondary axis on the right. 
Figure 12 shows the simulation results for a cloudy day in winter. Unlike the profiles on July $8^{\text {th }}$, the profiles on January $29^{\text {th }}$ have more up-and-down zigzag shapes. The CSP plant was switched between storage mode and transient mode with the two base-load power production settings according to the intermittent sunlight. From the storage volume profiles, it can be easily seen that the CSP plant was operating in transient mode from $11 \mathrm{am}$ to $12 \mathrm{pm}$, as the TDC storage increased and $\mathrm{H}_{2}$ storage decreased. The CSP plant was capable of extending the production hours to 1-2 hours after the sunlight disappeared. This is low compared to Solana Generating Station which claims a 6 hour storage capacity with the molten salt storage system [38], although based on their actual reported production, the actual average daily energy stored is more likely in the 2-3 hour range. In addition, the low storage capacity of the decalin-based system is largely explained by the low discharge efficiency, which produces only $18.8 \mathrm{MWh}$ of electricity per $100 \mathrm{MWh}$ of chemical energy stored (based on heats of formation). The large parasitic load of the compressors is a major factor in this low efficiency, which could be improved by changing the operating pressures of the forward and backwards reaction. However, this could not be explored in this study because no kinetic information on the forward and backward reaction at other pressures is available.

As mentioned above, the system slowly decays over cycles as NP builds up. If designing the system for one year's worth of cycles, the sizes of decalin, naphthalene, $\mathrm{H}_{2}$, and $\mathrm{N}_{2}$ storage tanks (as shown in Figure 1) were found to be $6 \times 10^{4} \mathrm{~m}^{3}, 3.8 \times 10^{4} \mathrm{~m}^{3}$, $4 \times 10^{4} \mathrm{~m}^{3}$, and $3 \times 10^{5} \mathrm{~m}^{3}$, respectively. However, one could consider using fresh $\mathrm{H}_{2}$ to convert the excessive NP back into TDC and CDC via the backward reactors at the end of each day. In this case, the storage sizes of decalin and naphthalene could be reduced to $1.7 \times 10^{3} \mathrm{~m}^{3}$ and $1.4 \times 10^{3} \mathrm{~m}^{3}$, respectively.

Compared to the existing CSP plant the Solana Generating Station, the proposed thermochemical storage system was relatively larger, but safer since chemicals were stored at much lower temperature. It was reported that Solana holds 125,000 metric tons of molten salt, which is around $5.7 \times 10^{4} \mathrm{~m}^{3}$ in volume. It requires smaller space than the thermochemical storage system, but the molten salt has to be stored at up to $390^{\circ} \mathrm{C}$ [2]. For the proposed thermochemical storage system, naphthalene would be stored at $82^{\circ} \mathrm{C}$ and the other chemicals could be stored at room temperature or ambient temperature. 

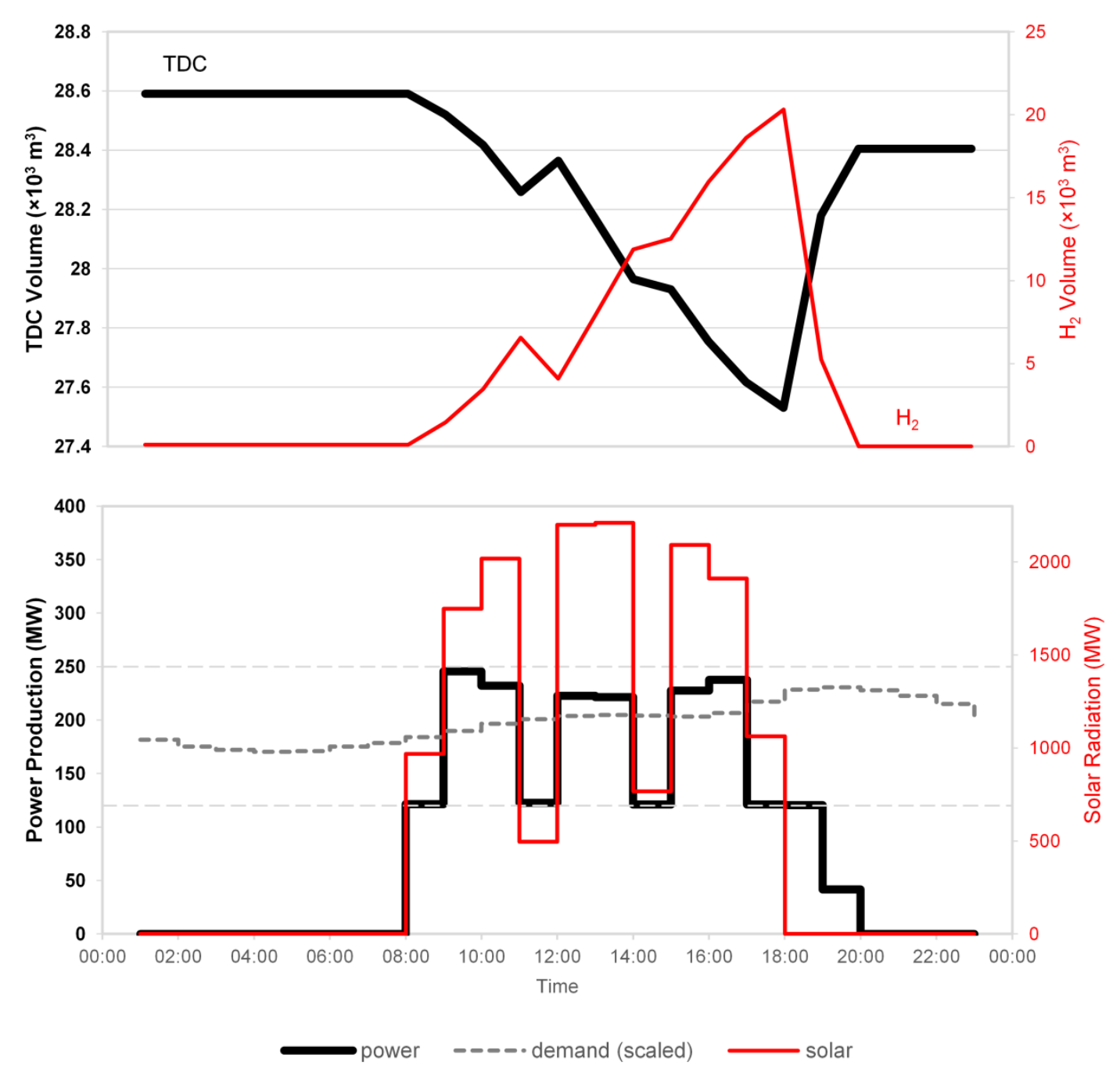

Figure 12. Model predicted electricity production profile and storage volume profiles of chemicals on January $29^{\text {th }}, 2012$. On the bottom figure, power production and demand curves are read from the primary axis on the left, and solar radiation is read from the secondary axis on the right.

\section{Conclusions and Future work}

In this work, the feasibility and effectiveness of an integrated DSG CSP plant with a decalin/naphthalene thermochemical storage system was investigated by simulations for 8784 cases in accordance to historical hourly solar radiation data over a year. It was found that the integrated plant was able to extend base-load power production for 1 to 2 hours when sunlight completely disappeared on a single day. The plant was proven to be feasible as it continuously stored and discharged energy to maintain the base-load power production with high conversion and reversibility of decalin/naphthalene reactions. 
However, it was found that the whole system was not completely reversible due to incomplete membrane separation of $\mathrm{H}_{2}$ from $\mathrm{N}_{2}$, meaning that the storage capabilities of the chemicals decayed over time. Thus, the system requires periodic recharging of the storage chemicals. Compared to molten salt storage system, the proposed decalin/naphthalene thermochemical storage system has lower storage temperature (at ambient temperature except naphthalene which is stored at $82^{\circ} \mathrm{C}$ ). If the gradual storage capacity degradation issue could be remedied, the required storage size would be smaller than the molten salt storage system. As an overall recommendation, the proposed integrated DSG CSP plant with a decalin/naphthalene thermochemical storage system could be a strong alternative to CSP plants with molten salt storage systems.

Since this work is the first known investigation of a DSG CSP plant with a decalin/naphthalene thermochemical storage system to the best of our knowledge, several assumptions were made during model simulations for this conceptual design, such as limiting possible reaction pressures to ranges in which the kinetics were known, instead of where they might be more optimal from a systems perspective. Therefore, additional experimental studies on the reaction kinetics in the pressure range of 2 - 35 bar would be very beneficial. Other future studies include developing a flow pattern model for the steam/water two-phase flow, formally optimizing the heat integration of the plant, analyzing alternatives to $\mathrm{H}_{2} / \mathrm{N}_{2}$ separations, system simulations for peaking power, and economic analyses. These future work considerations will likely affect the competitiveness of the proposed system as an alternative to other CSP plants.

\section{Acknowledgements}

Financial support from NSERC Discovery Grant (RGPIN-2016-06310), NSERC Canada Graduate Scholarships-Master's Program, and Ontario Graduate Scholarship Program are gratefully acknowledged. We also acknowledge Dr. Vida Meidanshahi (McMaster University) with first identifying the decalin/naphthalene chemical reaction pathway as a suitable candidate for CSP applications. 


\section{Nomenclature}

Abbreviations

TDC trans-decalin

CDC cis-decalin

TT tetralin

NP naphthalene

CSP concentrated solar power

DSG direct steam generation

PTC parabolic trough collectors

HTF heat transfer fluid

TES thermal energy storage

DNI direct normal irradiance

PSO particle swarm optimization

VBA visual basic for applications

HP high pressure turbine

IP intermediate pressure turbine

LP low pressure turbine

Variables

$r, r^{\prime}, r_{r}, r_{r}^{\prime}$ reaction rate

W work

V vapour fraction

$k_{s}, k_{s}{ }^{\prime} \quad$ reaction rate constant

$K \quad$ adsorption equilibrium constant

$P \quad$ pressure

$A \quad$ frequency factor 


\begin{tabular}{ll}
$E$ & activation energy \\
$R$ & gas constant \\
$T$ & temperature \\
$H$ & enthalpy \\
$F$ & flowrate \\
$W$ & catalyst weight \\
$\eta$ & correction factor \\
$\dot{V}$ & volumetric flowrate \\
$\rho$ & density \\
$\mathcal{E}$ & porosity \\
$D$ & diameter \\
$V$ & superficial velocity \\
$\mu$ & viscosity \\
$A c s$ & cross-sectional area \\
$C_{p}$ & heat capacity \\
$A$ & area \\
$\beta$ & reaction stoichiometry \\
$\dot{M}$ & mass flowrate \\
$U$ & overall heat transfer coefficient \\
$h$ & heat transfer coefficient \\
$N$ tube & number of tubes \\
$L$ & reactor length \\
$k$ & thermal conductivity \\
$R e$ & Reynolds number \\
$P r$ & Prandtl number \\
$\alpha$ & gas hold up \\
& \\
\hline &
\end{tabular}




\section{References:}

[1] P. Pardo, A. Deydier, Z. Anxionnaz-Minvielle, S. Rougé, M. Cabassud, and P. Cognet, "A review on high temperature thermochemical heat energy storage," Renew. Sustain. Energy Rev., vol. 32, pp. 591-610, Apr. 2014.

[2] 12/01/2014 | Dr Robert Peltier and PE, "Top Plant: Solana Generating Station, Maricopa County, Arizona," POWER Magazine, 01-Dec-2014. .

[3] L. Valenzuela, E. Zarza, M. Berenguel, and F. Camacho, "Direct steam generation in solar boilers," Control Syst. Mag. IEEE, vol. 24, no. 2, pp. 15-29, 2004.

[4] J. F. Feldhoff, "Direct Steam Generation (DSG) - Technology Overview," presented at the SFERA Summer School 2012, Spain, 28-Jun-2012.

[5] J. Birnbaum, M. Eck, M. Fichtner, T. Hirsch, D. Lehmann, and G. Zimmermann, "A Direct Steam Generation Solar Power Plant With Integrated Thermal Storage," J. Sol. Energy Eng., vol. 132, no. 3, pp. 031014-031014, Jun. 2010.

[6] B. Wang, D. W. Goodman, and G. F. Froment, "Kinetic modeling of pure hydrogen production from decalin," J. Catal., vol. 253, no. 2, pp. 229-238, Jan. 2008.

[7] J. Cot-Gores, A. Castell, and L. F. Cabeza, "Thermochemical energy storage and conversion: A-state-of-the-art review of the experimental research under practical conditions," Renew. Sustain. Energy Rev., vol. 16, no. 7, pp. 5207-5224, Sep. 2012.

[8] T.-C. Huang and B.-C. Kang, "Kinetic Study of Naphthalene Hydrogenation over Pt/Al2O3 Catalyst," Ind. Eng. Chem. Res., vol. 34, no. 4, pp. 1140-1148, Apr. 1995.

[9] "Abengoa Solar :: Solar plants :: Third party plants :: United States." [Online]. Available: http://www.abengoasolar.com/web/en/plantas_solares/plantas_para_terceros/estados_uni dos/. [Accessed: 10-Mar-2017].

[10] Abengoa Solar, "A New Generation of Parabolic Trough Technology," presented at the SunShot CSP Program Review 2013, Phoenix, AZ, Apr-2013.

[11] Air Products, "PRISM® PB6050 Membrane Separators for hydrogen separation in glycol manufacturing." 2017.

[12] W. M. Haynes, CRC Handbook of Chemistry and Physics, 91st Edition. Taylor \& Francis, 2010.

[13] "NSRDB: 1991- 2010 Update." [Online]. Available: http://rredc.nrel.gov/solar/old_data/nsrdb/1991-2010/. [Accessed: 20-Oct-2016].

[14] P. Nasir, R. J. Martin, and R. Kobayashi, "A novel apparatus for the measurement of the phase and volumetric behavior at high temperatures and pressures and its application to study VLE in the hydrogen-tetralin system," Fluid Phase Equilibria, vol. 5, no. 3, pp. 279288, Jan. 1981.

[15] W. Gao, K. A. M. Gasem, and R. L. Robinson, "Solubilities of Nitrogen in Selected Naphthenic and Aromatic Hydrocarbons at Temperatures from 344 to $433 \mathrm{~K}$ and Pressures to 22.8 MPa," J. Chem. Eng. Data, vol. 44, no. 2, pp. 185-189, Mar. 1999.

[16] J. Park, R. L. Robinson, and K. A. M. Gasem, "Solubilities of Hydrogen in Aromatic Hydrocarbons from 323 to $433 \mathrm{~K}$ and Pressures to $21.7 \mathrm{MPa}$," J. Chem. Eng. Data, vol. 41, no. 1, pp. 70-73, Jan. 1996.

[17] Y. Miyake, A. Baylaucq, C. K. Zéberg-Mikkelsen, G. Galliéro, H. Ushiki, and C. Boned, "Stereoisomeric effects on volumetric properties under pressure for the system cis- + trans-decalin," Fluid Phase Equilibria, vol. 252, no. 1-2, pp. 79-87, Mar. 2007.

[18] Y. Khojasteh Salkuyeh and T. A. Adams, "A novel polygeneration process to co-produce ethylene and electricity from shale gas with zero $\mathrm{CO} 2$ emissions via methane oxidative coupling," Energy Convers. Manag., vol. 92, pp. 406-420, Mar. 2015.

[19] J. Sanz-Bermejo, V. Gallardo-Natividad, J. Gonzalez-Aguilar, and M. Romero, "Comparative System Performance Analysis of Direct Steam Generation Central Receiver 
Solar Thermal Power Plants in Megawatt Range," J. Sol. Energy Eng., vol. 136, no. 1, pp. 010908-010908-9, Jan. 2014.

[20] L. Haar, Nbs/Nrc Steam Tables. CRC Press, 1984.

[21] F. A. Aly and L. L. Lee, "Self-consistent equations for calculating the ideal gas heat capacity, enthalpy, and entropy," Fluid Phase Equilibria, vol. 6, no. 3, pp. 169-179, Jan. 1981.

[22] R.C Reid, J.M Prausnitz, and B.E Poling, The Properties of Gases and Liquids, 4th ed. New York: McGraw-Hill, 1987.

[23] H. G. Rackett, "Equation of state for saturated liquids," J. Chem. Eng. Data, vol. 15, no. 4, pp. 514-517, Oct. 1970.

[24] L. J. Alvarez, L. E. Leon, J. F. Sanz, M. J. Capitan, and J. A. Odriozola, "Computer Simulation of .gamma.-Al2O3 Microcrystal," J. Phys. Chem., vol. 99, no. 51, pp. 1787217876, Dec. 1995.

[25] T. A. Adams and P. I. Barton, "A dynamic two-dimensional heterogeneous model for water gas shift reactors," Int. J. Hydrog. Energy, vol. 34, no. 21, pp. 8877-8891, Nov. 2009.

[26] J. H. Ghouse and T. A. Adams, "A multi-scale dynamic two-dimensional heterogeneous model for catalytic steam methane reforming reactors," Int. J. Hydrog. Energy, vol. 38, no. 24, pp. 9984-9999, Aug. 2013.

[27] S. Ergun and A. A. Orning, "Fluid Flow through Randomly Packed Columns and Fluidized Beds," Ind. Eng. Chem., vol. 41, no. 6, pp. 1179-1184, Jun. 1949.

[28] J. M. 1916- Smith, Chemical engineering kinetics, 3d ed.--. McGraw-Hill, 1981.

[29] F. P. Incropera, D. P. Dewitt, T. L. Bergman, and A. S. Lavine, Introduction to Heat Transfer, 6th ed. Wiley and Sons, 2011.

[30] C. A. Harper, Handbook of plastics technologies: the complete guide to properties and performance. McGraw-Hill, 2006.

[31] J. M. Coulson and J. F. Richardson, Chemical engineering, 2nd ed. (SI units). Oxford ; New York: Pergamon Press, 1979.

[32] B. V. Babu and V. G. Rao, Thermal Resistance Models for Effective Heat Transfer Parameters in Trickle Bed Reactors. 2007.

[33] N. Wakao, Heat and mass transfer in packed beds. Gordon and Breach Science Publishers, 1982.

[34] C. E. Brennen, Fundamentals of Multiphase Flow. Cambridge University Press, 2005.

[35] R. Perry and D. Green, Perry's Chemical Engineers' Handbook, Eighth Edition. McGrawHill Education, 2008.

[36] M. S. Peters and K. D. Timmerhaus, Plant design and economics for chemical engineers. McGraw-Hill, 1991.

[37] M. Tooley and L. Dingle, Engineering Science: For Foundation Degree and Higher National. Routledge, 2013.

[38] "Concentrating Solar Power Projects - Solana Generating Station | Concentrating Solar Power | NREL." [Online]. Available: https://www.nrel.gov/csp/solarpaces/project_detail.cfm/projectlD=23. [Accessed: 27-Jan2017].

[39] "Electricity data browser - Solana Generating Station." [Online]. Available: https://www.eia.gov/electricity/data/browser/\#/plant/56812. [Accessed: 21-Feb-2017].

[40] "IESO Home." [Online]. Available: http://www.ieso.ca/. [Accessed: 01-Nov-2016]. 